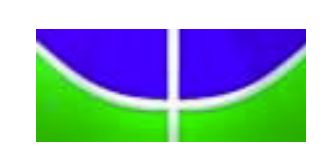

UNIVERSIDADE DE BRASÍLIA

Centro de Excelência em Turismo

Pós-Graduação Lato Sensu

Curso de Especialização em Tecnologia dos Alimentos

\title{
SUBSTITUTOS DE GORDURAS APLICADOS EM ALIMENTOS PARA FINS ESPECIAIS
}

Andrea Alves Dias

Orientadora: Prof ${ }^{\mathrm{a}}$ Lívia L.O. Pineli 


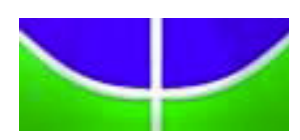

UNIVERSIDADE DE BRASÍLIA

Centro de Excelência em Turismo

Pós-Graduação Lato Sensu

Curso de Especialização em Tecnologia dos Alimentos

\title{
SUBSTITUTOS DE GORDURAS APLICADOS EM ALIMENTOS PARA FINS ESPECIAIS
}

\author{
Andrea Alves Dias \\ Orientadora: Prof ${ }^{a}$ Lívia L.O. Pineli
}

Monografia apresentada ao Centro de Excelência em Turismo - CET, da Universidade de Brasília - UnB como requisito parcial á obtenção do grau de Especialista em Tecnologia dos Alimentos. 
Dias, Andrea Alves

Substitutos de gorduras aplicados em alimentos para fins especiais Brasília, 2007.

Monografia (especialização) - Universidade de Brasília, Centro de Excelência em Turismo, 2007.

Orientadora: Livia L.O. Pineli.

1. Nutrição. 2. Substitutos de gorduras. 3. Alimentos para fins especiais. I. Título. II. Título. 
UNIVERSIDADE DE BRASÍLIA

Centro de Excelência em Turismo

Pós-Graduação Lato Sensu

Curso de Especialização em Tecnologia dos Alimentos

\section{Andrea Alves Dias}

\section{Aprovado em:}

Orientadora: Lívia L.O.Pineli

Dra Raquel Braz Assunção Botelho

Dra Wilma Maria Coelho Araújo

Brasília, 19 de março de 2007. 
Agradeço primeiramente a Deus, por ter me iluminado a cada dia na elaboração desse trabalho. Agradeço à professora Lívia L.O.Pineli que me acolheu com muito carinho e prestou uma ajuda imensurável nesta monografia. E aos meus pais, irmãos, namorado e avós pela compreensão e apoio que me deram durante essa caminhada. 


\section{RESUMO}

Este trabalho apresenta a evolução da Tecnologia de Alimentos, no que diz respeito aos substitutos de gorduras para fins especiais, utilizados nas indústrias alimentícias com objetivo de ampliar, para os consumidores que buscam uma alimentação mais saudável ou que necessitam devido alguma patologia, a variedade de produtos com baixa caloria e baixo teor lipídico. Nesta revisão bibliográfica enfocam-se os tipos de substitutos de gorduras; a preocupação das indústrias alimentícias em fornecer produtos à base de substitutos de gorduras com a mesma qualidade dos produtos convencionais; os substitutos que possuem selo de garantia pela FDA; os estudos científicos que desenvolveram produtos com os vários tipos de substitutos de gordura existentes, com as mesmas características organolépticas dos lipídeos e sua aceitação potencial no mercado.

PALAVRAS-CHAVE: Substitutos de gorduras, indústrias alimentícias, lipídeos. características organolépticas, legislação de alimentos para fins especiais. 


\begin{abstract}
This work presents the evolution of the Food Technology, in what it refers to fat replacers used in diet food, with the aim to enlarge the variety of products with low calorie and low fat content, for consumers who look for a healthier food or who need it when they have a pathology. In this revision, fat replacers types are described; the worry of food industries to supply diet food with fat replacers as good as conventional products are discussed; fat replacers with safety certification of FDA are cited; the scientific studies in wich products with several sorts of food replacers were developed, with the same flavor characteristics of conventional food and their potential acceptance in market place.
\end{abstract}

KEYWORDS: Fat replacers, food industry, lipids, flavor characteristics, diet food legislation. 


\section{SUMÁRIO}

1. INTRODUÇÃ

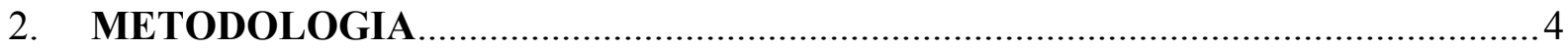

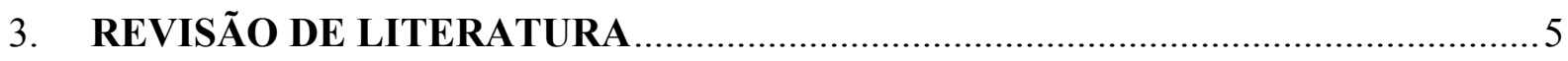

3.1 Estudos sobre a transição nutricional da população brasileira ..................................5

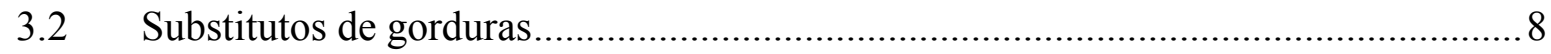

3.2.1 Tipos de substitutos de gorduras utilizados nas indústrias .............................

3.2.2 Substitutos de gorduras a base de proteínas ................................................. 10

3.2.3 Substitutos de gorduras a base de carboidratos .........................................20

3.2.4 Substitutos de gorduras a base de produtos similares a gorduras..................... 36

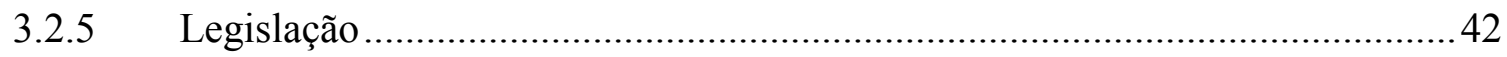

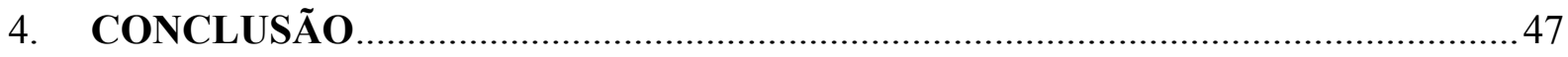

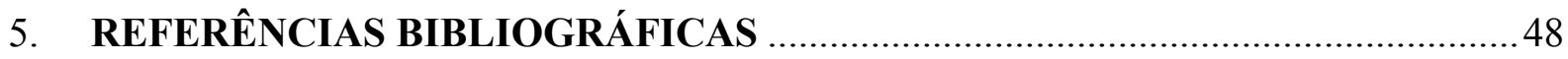




\section{INTRODUÇÃO}

A gordura é um elemento de grande importância na alimentação humana por suas propriedades nutricionais, funcionais e organolépticas. É vital para o metabolismo pleno do organismo humano, pois fornece ácidos graxos essenciais necessários à estrutura das membranas celulares e prostaglandinas, além de servir como transportadora das vitaminas lipossolúveis A, D, E e K. Os lipídeos são responsáveis por propriedades como firmeza, adesividade, elasticidade, paladar, cremosidade e ação lubrificante nos alimentos (LIMA; NASSU, 1996).

A energia fornecida pelas gorduras é de $9 \mathrm{kcal} / \mathrm{g}$, aproximadamente o dobro de calorias fornecidas pelas proteínas e carboidratos. Apesar de sua importância na saúde, estudos epidemiológicos, clínicos e biológicos têm demonstrado existir alta correlação entre o excesso de gorduras na dieta e os riscos de doenças cardiovasculares, quando associados ao elevado teor de colesterol sangüíneo e à incidência de certos tipos de câncer (especialmente do cólon, mama e próstata), diabetes e diminuição da expectativa de vida. Isso tem preocupado os consumidores, levando-os a serem cada vez mais cautelosos quanto ao consumo de gorduras e alterando, assim, seus hábitos alimentares (VIANA et al., 2003).

No Brasil houve uma rápida transição demográfica e nutricional no período de 1960-1990, o que consistiu na alteração da estrutura de ocupações e empregos, passando de um mercado de trabalho fundado no setor primário (agropecuária e extrativismo) para uma demanda de mão-de-obra concentrada no setor secundário e, sobretudo, no setor terciário da economia. As mulheres deixaram de trabalhar apenas como donas-de-casa e começaram procurar empregos com o objetivo da obtenção da independência financeira. Essas são transformações cruciais, no que se refere à geração de renda, estilos de vida e, especificamente, demandas nutricionais da população brasileira (MONDINI; MONTEIRO, 1994).

Segundo Bleil (1998), a indústria alimentícia norte-americana tem elaborado diversas preparações congeladas (alimentos de conveniência) e têm conquistado um público crescente (crianças, adolescentes e adultos), principalmente nos grandes centros. A publicidade e a ideologia de consumo desses novos produtos favorecem a formação de novos hábitos, inimagináveis há pouco mais de três décadas. Atualmente, essa modalidade de alimentação é uma realidade de milhões de brasileiros; isso se deve, em 
parte, à mentalidade moderna, globalmente presente, difundindo o desejo de consumo ilimitado e, em parte, à idéia da supremacia do conhecimento técnico e científico, associados aos hábitos importados.

O feijão, a farinha de mandioca, o arroz e a farinha de milho, os alimentos mais tradicionais na dieta do brasileiro, têm sofrido redução em seu consumo. Percebe-se que a fome, hoje, é resultante não só da pouca disponibilidade de alimentos, para os grupos de baixa renda, mas, também, da redução da qualidade dos alimentos, excessivamente industrializados. Isto pode ser constatado tanto $\mathrm{n}$ os casos de anemia como nos de obesidade, como grandes problemas de saúde pública, atingindo a todos os estratos sociais. Conclui-se que a atual invasão cultural presente no Brasil tem facilitado a entrada destes novos produtos e hábitos.

Esses novos padrões alimentares têm levado a grande ocorrência de enfermidades crônico não transmissíveis, como as doenças cardiovasculares, e ao aumento da obesidade na população. Em conseqüência, as pessoas estão, atualmente, muito mais preocupadas com os seus hábitos alimentares e com sua saúde e estão à procura de produtos que ofereçam mais qualidade na alimentação.

Para atender a expectativa de pessoas que procuram, nos produtos de baixa caloria, a mesma qualidade dos produtos convencionais, como sabor e textura adequados, ausência de colesterol e baixo teor de gorduras, os pesquisadores têm desenvolvido numerosos substitutos de gorduras. O objetivo é a obtenção de alimentos com as propriedades organolépticas e funcionais das gorduras, sem seu elevado teor calórico (CÂNDIDO, 1996).

Esses substitutos são produtos com características de gorduras que possuem menor valor calórico. São utilizados com a finalidade de substituir a gordura tradicional existente nos alimentos, com objetivo de buscar e oferecer alternativas para as pessoas que necessitam de uma alimentação saudável, seja por problemas de saúde ou porque buscam uma melhor qualidade de vida (CÂNDIDO, 1996).

Este trabalho tem como objetivo geral descrever os tipos de substitutos de gorduras e suas aplicações nas indústrias de alimentos e, como objetivos específicos, descrever a importância dos lipídeos quanto aos aspectos nutricionais e funcionais dos alimentos, descrever as características, propriedades e mecanismo de ação dos substitutos de gorduras e suas aplicações no processamento de produtos "diet" e "light"; pesquisar a 
legislação sobre os substitutos de gorduras e alimentos para fins especiais e mostrar algumas preparações com menor teor de gordura e valor calórico, realizadas em estudos com vários substitutos de gorduras, evidenciando a aceitabilidade das aplicações avaliadas. 


\section{METODOLOGIA}

A pesquisa foi realizada por meio de revisão bibliográfica, a qual foi executada no período de janeiro de 2007, com o objetivo de conhecer os tipos de substitutos de gorduras utilizados nas indústrias de alimentos para fins especiais.

Foram procuradas informações sobre substitutos de gorduras em artigos científicos nos sites de periódicos da CAPES e do SCIELO, em Português e Inglês; em Revistas Científicas na área de Nutrição e no site da Agência Nacional de Vigilância Sanitária - ANVISA, para levantamento da legislação pertinente. 


\section{REVISÃO DE LITERATURA}

\subsection{Estudos sobre a transição nutricional da população brasileira}

São escassos os estudos de base populacional, produzidos, até hoje, com a população brasileira, cujo enfoque principal seja os problemas nutricionais. Como exemplos, devemos destacar o Estudo Nacional sobre Despesas Familiares - ENDEF, realizado entre 1974 e 1975; a Pesquisa Nacional sobre Saúde e Nutrição - PNSN, de 1989 e, mais recentemente, a Pesquisa sobre Padrões de Vida - PPV, desenvolvida em 1997. A adequada análise dos resultados desses estudos foi de grande importância por várias razões: permitiu avaliar a magnitude dos agravos nutricionais mais relevantes, bem como mapear alguns dos seus principais determinantes; depois de realizados em intervalos sistemáticos, permitiu estudar a tendência dos problemas nutricionais (IBGE, 2004).

De acordo com o Ministério da Saúde - MS, as projeções para as próximas décadas apontam para um crescimento epidêmico das Doenças Crônicas Não-Transmissíveis - DCNT na maioria dos países em desenvolvimento, em particular das doenças cardiovasculares e diabete tipo II. Os dois principais determinantes desse crescimento são aumento na intensidade e freqüência da exposição aos principais fatores de risco para essas doenças, quais sejam: hipertensão arterial, hipercolesterolemia, pouca ingestão de frutas e hortaliças, excesso de peso ou obesidade, falta de atividade física e consumo de tabaco (BRASIL, 2004).

De acordo com o Relatório Técnico 916 da Organização Mundial da Saúde - OMS sobre Alimentação Saudável, Atividade Física e Saúde, há provas científicas de que as pessoas podem manter-se saudáveis depois dos 70, 80 e 90 anos, se tiverem alimentação adequada, prática regular de atividade física e se não fumarem. Nas populações em geral vêm aumentando os fatores de risco (que coexistem e interagem) e o nível de exposição. Por conseguinte, as estratégias de prevenção devem se propor a reduzir os riscos. A alimentação saudável e a prática de atividade física, junto com o controle do tabaco, podem trazer amplos benefícios e constituir a melhor estratégia para melhorar a qualidade de vida e conter a crescente ameaça mundial das Doenças Crônicas Não-Transmissíveis - DCNT.

O crescimento do número de casos de sobrepeso e obesidade nas últimas décadas tem revelado um quadro epidemiológico preocupante acerca do grupo de DCNT. A obesidade, integrante deste grupo, é um recente problema de saúde pública no Brasil. A população adulta brasileira vem apresentando um aumento importante na prevalência de excesso de peso. De 
acordo com os dados do inquérito nacional mais recente, PNSN -1989, (SAÚDE, 2003 citado por PINHEIRO, 2004), cerca de 32\% dos adultos brasileiros apresentam algum grau de excesso de peso; destes 6,8 milhões de indivíduos (8\%) apresentam obesidade, com predomínio entre as mulheres $(70 \%)$. A prevalência ainda se acentua com a idade, atingindo um valor maior na faixa etária de 45 - 54 anos (37\% entre homens e 55\% entre mulheres).

No período compreendido entre os dois inquéritos nacionais (1975-1989), houve um aumento de $100 \%$ na prevalência de obesidade entre os homens e de $70 \%$ entre as mulheres, considerando todas as faixas etárias. Em todas as regiões do país, parcelas significativas da população adulta apresentam sobrepeso e obesidade. Em termos relativos, a situação mais crítica é verificada na região Sul, onde $34 \%$ dos homens e $43 \%$ das mulheres apresentaram algum grau de excesso de peso, totalizando aproximadamente cinco milhões de adultos em 1989. No entanto, ao verificar dados absolutos, situa-se na região Sudeste a maior quantidade de adultos com excesso de peso no país, totalizando mais de dez milhões de adultos com sobrepeso e cerca de três milhões e meio com obesidade (PINHEIRO, 2004).

$\mathrm{O}$ aumento da prevalência da obesidade no Brasil torna-se ainda mais relevante ao se considerar que, apesar de estar distribuído em todas as regiões do país e nos diferentes estratos sócio-econômicos da população, é proporcionalmente mais elevado nas famílias de baixa renda.

A Pesquisa sobre Padrões de Vida foi realizada pelo Instituto Brasileiro de Geografia e Estatística - IBGE, em 1997 (BRASIL, 1999), sendo restrita às regiões Nordeste e Sudeste, onde estão concentrados mais de três quartos da população brasileira. Estas duas regiões ocupam pólos opostos - inferior e superior, respectivamente, em relação à distribuição regional dos indicadores do desenvolvimento, como os indicadores econômicos (produção de bens e serviços, valor dos salários, renda per capita) e os indicadores sociais: taxa de mortalidade infantil, esperança de vida e escolaridade da população (PINHEIRO, 2004).

Monteiro (2000) analisou as prevalências de obesidade específicas por sexo e faixa etária estimada pelos inquéritos realizados em 1974/75, 1989 e pela PPV de 1997. Para tornar possível a comparação com o inquérito mais recente, considerou, nos inquéritos anteriores, apenas a amostra relativa às regiões Nordeste e Sudeste. As modificações nas prevalências da obesidade entre 1989 e 1997 revelaram que, no caso dos homens, embora a prevalência da obesidade siga aumentando nas duas regiões, está em elevação de modo mais intenso na Região Nordeste, induzindo ao risco de a obesidade masculina, nesta região, se aproximar daquele existente na região Sudeste. 
Nas mulheres, a prevalência da obesidade aumenta de forma notável na Região Nordeste, mas mantém-se estável ou, mesmo, tende a diminuir, em algumas faixas etárias, na Região Sudeste. As diferenças no padrão regional de evolução evidenciam que o risco de obesidade feminina na Região Nordeste, em 1997, tende a se igualar ou mesmo a superar o risco da patologia na Região Sudeste.

Nesta análise, pode-se considerar o efeito do fenômeno da urbanização e o seu impacto sobre padrões de atividade física e características da alimentação. Ao analisar dados sobre tendência secular do consumo alimentar (restritos à comparação entre as áreas metropolitanas do país), as alterações de maior destaque referem-se à tendência ao aumento da densidade energética das dietas, o que se observa especialmente entre os inquéritos de 1974/75 e 1987/88, com o aumento de 2 a 7 pontos percentuais na proporção da energia procedente do consumo de lipídios.

A urbanização, sem dúvida, parece ter induzido a uma mudança nos padrões de vida e comportamento alimentar das populações. No Brasil, os tipos de alimentos consumidos na zona rural são muito diferentes daqueles consumidos na zona urbana, o que está relacionado diretamente ao poder aquisitivo ou ao nível socioeconômico (MONTEIRO, 2000).

É importante salientar que esses estudos, quando bem explorados, constituem-se um bom instrumento para a discussão sobre transição nutricional feita no Brasil até aos dias de hoje. Entende-se por transição nutricional o fenômeno pelo qual ocorre uma inversão nos padrões de distribuição dos problemas nutricionais de uma dada população, no tempo. Em outros termos, é uma mudança na magnitude e no risco atribuível dos agravos associados a doenças identificadas ao atraso e à modernidade, sendo em geral, uma passagem dos estados gerais de desnutrição para os de obesidade.

Estudos demonstram que a população urbana de baixa renda apresenta uma ingestão calórica inferior, quando comparada com a população rural, apesar de que a primeira consome proporcionalmente mais proteína e gordura animal do que a segunda. A população urbana consome maior quantidade de alimentos processados, como carnes, gorduras, açúcares e derivados do leite, em relação à área rural, em que a ingestão de cereais, raízes e tubérculos é mais elevada (FILHO; RISSIN, 2003).

A obesidade se consolidou com o agravo nutricional associado a uma alta incidência de doenças cardiovasculares, câncer e diabetes, influenciando, desta maneira, no perfil de morbi-mortalidade das populações. Apontam-se, como determinantes, o estilo de vida sedentário e o consumo de dietas inadequadas e, mais que tudo, clama-se por uma maior diversidade de intervenções e de apoio governamental, com a implementação de ações claras 
de prevenção e de combate à obesidade. A obesidade hoje não se resume mais a um problema presente apenas nos países ditos desenvolvidos, mas, sim, afeta cada vez maiores parcelas dos estratos populacionais menos favorecidos (KAC; MELÉNDEZ, 2003).

Em um país como o Brasil, em que as desigualdades regionais são imensas, é importante destacar que a garantia da segurança alimentar e nutricional pressupõe a necessidade de estratégias de saúde pública, capazes de dar conta de um modelo de atenção à saúde e ao cuidado nutricional, direcionados para os problemas da desnutrição e do sobrepeso / obesidade, uma vez que estes distúrbios nutricionais, e todas as doenças relacionadas à alimentação e nutrição, revelam duas faces, diversas e aparentemente paradoxais, de um mesmo problema: a insegurança alimentar e nutricional da população brasileira (FILHO; RISSIN, 2003).

É incontestável que o Brasil e diversos países da América Latina estão experimentando nos últimos vinte anos uma rápida transição demográfica, epidemiológica e nutricional. As características e os estágios de desenvolvimento da transição diferem para os vários países da América Latina (KAC; MELÉNDEZ, 2003).

\subsection{Substitutos de gorduras}

Com os altos índices de obesidade em diversos países e suas patologias associadas, criou-se a necessidade de produtos alimentares com baixos teores de gorduras, açúcares e calorias, para pessoas que sofrem dessa enfermidade ou que procuram uma alimentação mais saudável.

Para atender a expectativa de pessoas que procuram nos produtos de baixa caloria a mesma qualidade que nos produtos convencionais, como sabor e textura adequados, ausência de colesterol e baixo teor de gorduras, instituições públicas e privadas têm-se dedicado a crescentes esforços de pesquisa, para desenvolvimento de melhores ingredientes e métodos de produção. O objetivo é a obtenção de alimentos com as propriedades organolépticas e funcionais das gorduras, sem seu elevado teor calórico (CÂNDIDO, 1996). Surgiram, assim, produtos de baixíssimo teor de lipídeos, que possuem, em seu lugar, outros compostos com propriedades semelhantes às das gorduras, denominados substitutos de gorduras.

Os substitutos de gorduras são produtos que mimetizam o sabor, a textura, a aparência, a viscosidades e outras propriedades das gorduras, porém com menor valor calórico (UIERA, 2002). 
O Codex Alimentarius (1994) utiliza o termo genérico substituto de gordura (fat replacer) para indicar a remoção total ou parcial e conseqüente substituição de gorduras por um sistema de produtos substitutos (CÂNDIDO, 1996).

Para ser utilizada como substituto de gordura, uma molécula precisa atender a alguns requisitos: deve ser livre de efeitos tóxicos; não deve produzir metabólitos diferentes daqueles produzidos pela gordura convencional, deve ser eliminada completamente do organismo e os produtos devem ser preferencialmente considerados Generally Recognised as Safe - GRAS, pela Food and Drug Administration - FDA (ZAMBRANO et al., 2005; UIERA, 2002).

\subsubsection{Tipos de substitutos de gorduras utilizados nas indústrias}

Diferentes tipos de substitutos de gorduras estão disponíveis no mercado e sua classificação está baseada, principalmente, na natureza química e na origem do produto, juntamente com seu valor energético. Os substitutos de gordura podem ser compostos de carboidratos, proteínas e lipídeos (SIVIERI; OLIVEIRA, 2002).

Os produtos existentes enquadram-se em dois grupos principais, de acordo com seu mecanismo de ação:

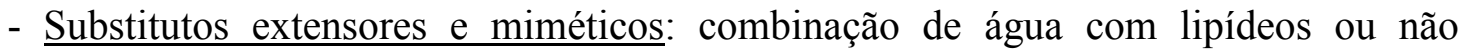
lipídeos (carboidratos ou proteínas modificadas) com propriedades emulsificantes ou capazes de formar géis especiais. Os extensores incluem produtos convencionais como amidos, gomas e maltodextrina associados a pequenas concentrações de gordura, que normalmente atuam como agentes de corpo. Os miméticos são carboidratos ou proteínas que podem simular algumas das propriedades das gorduras nos alimentos.

- Substitutos análogos de lipídeos: compostos não calóricos com propriedades semelhantes aos lipídeos, cujas ligações ésteres são modificadas (éteres, ésteres de lipídeos com açúcares, com poliglicerol, com polietilenoglicol). Estes são denominados de gorduras sintéticas, constituindo-se em substâncias com as propriedades funcionais de gorduras, mas que o organismo não consegue metabolizar e que seriam o que se pode chamar literalmente de substitutos de gordura (CÂNDIDO, 1996). 


\subsubsection{Substitutos de gorduras a base de proteínas}

Os substitutos de gordura a base de proteínas (Tabela 1), atualmente comercializados são, em sua maioria, produtos convencionalmente utilizados e de segurança estabelecida. Aparecem na forma hidratada e têm aplicação seletiva em alimentos.

O elemento comum nos sistemas de substituição de gorduras é a água. O sucesso depende do controle desta água, de forma a que o substituto proporcione a funcionalidade da gordura ausente ou em teor reduzido (CÂNDIDO, 1996).

As proteínas apresentam aplicação limitada como substitutos de gorduras, por não poderem ser utilizados em panificação e para frituras, devido às altas temperaturas alcançadas nestes processos. $\mathrm{O}$ aquecimento provoca coagulação e desnaturação das proteínas, resultando em perda de cremosidade e textura. Além disso, interage com componentes do sabor, diminuindo-lhes a intensidade ou contribuindo para a ocorrência de sabor desagradável (LIMA; NASSU, 1996).

Tabela 1: Tipos de substitutos de gorduras a base de proteínas

\begin{tabular}{|c|c|c|c|}
\hline Tipos de proteínas & Produtos & Fonte & Aplicação \\
\hline Proteína microparticulada & $\begin{array}{l}\text { - Simplesse }{ }^{\circledR} \\
\text { - LITA® }\end{array}$ & $\begin{array}{l}\text { - Leite } \\
\text { - Ovos }\end{array}$ & $\begin{array}{l}\text { - Sorvetes } \\
\text { - Queijos } \\
\text { - Produtos cárneos } \\
\text { - Requeijão, etc. }\end{array}$ \\
\hline Proteínas modificadas & - Traiblazer $\mathbb{R}$ & $\begin{array}{l}\text { - Albumina (ovo) } \\
\text { - Proteínas do } \\
\text { leite }\end{array}$ & $\begin{array}{l}\text { - Substitutos de } \\
\text { carnes } \\
\text {-Sobremesas geladas }\end{array}$ \\
\hline Proteínas derivadas do leite & 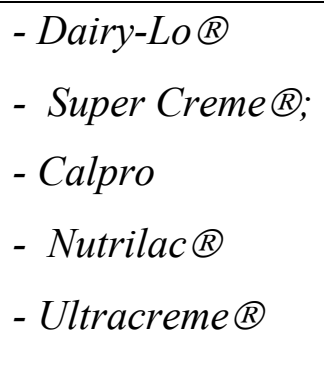 & $\begin{array}{l}\text { - Caseína } \\
\text { - } \alpha \text { lactalbumina, } \\
\text { - } \beta \text { lactoglobulina }\end{array}$ & $\begin{array}{l}\text { - Queijos } \\
\text { - Iogurtes } \\
\text { - Cremes } \\
\text { - Molhos } \\
\text { - Produtos de } \\
\text { panificação }\end{array}$ \\
\hline
\end{tabular}


Tabela 1: Tipos de substitutos de gorduras a base de proteínas (continuação)

\begin{tabular}{|l|l|l|l|}
\hline \multicolumn{1}{|c|}{ Tipos de proteínas } & \multicolumn{1}{|c|}{ Produtos } & \multicolumn{1}{c|}{ Fonte } & \multicolumn{1}{c|}{ Aplicação } \\
\hline Proteínas da soja & & & $\begin{array}{l}\text { - Produtos cárneos de } \\
\text { baixo teor de gordura } \\
\text { - Bebidas } \\
\text { - Produtos crocantes } \\
\text { - Suplementos } \\
\text { dietéticos }\end{array}$ \\
\hline Gelatina & - & - Soja & $\begin{array}{l}\text { - Margarinas } \\
\text {-Patês } \\
\text { - Sorvetes, iogurtes }\end{array}$ \\
\hline
\end{tabular}

Fonte: CÂNDIDO, 1996

Os ingredientes disponíveis como substitutos de gorduras atuam como modificadores de textura para simular a sensação bucal de alimentos ricos em gorduras.

A importância maior das proteínas como substituto de gorduras reside em sua habilidade de originar micropartículas. O tamanho das micropartículas, o volume da hidratação e as propriedades de superfície afetam a habilidade das proteínas de simular gorduras (CÂNDIDO, 1996).

Os substitutos a base de proteínas são geralmente derivados de proteínas encontradas em ovos, leite, milho e outros alimentos. Quando em altas concentrações (acima de 10\%), as proteínas do soro do leite possuem propriedades funcionais para serem utilizadas como substitutos de gorduras. Estes concentrados protéicos são considerados Generally Recognized as Safe - GRAS, pela Food and Drug Administration - FDA e são os substitutos de base protéica mais utilizados (LUCA; TEPPER, 1994).

Misturas de proteínas de clara de ovo e leite com outros produtos como açúcares, pectina e ácidos são utilizadas comercialmente para produção de substitutos de gordura mais complexos e completos. Muitas vezes a microparticulação é utilizada na produção destes compostos (CÂNDIDO, 1996).

A micropraticulação consiste na aplicação de calor às proteínas, de maneira que coagulem na forma de gel, ao mesmo tempo em que se submete o sistema a uma força de cisalhamento, fazendo que as proteínas coaguladas formem partículas de diâmetro de 0,1 a 2,0 $\mu \mathrm{m}$ (LIMA; NASSU, 1996). 
O tamanho de partículas desta ordem, pois aquelas de diâmetro igual ou inferior a 3,0 $\mu \mathrm{m}$ não são percebidas como partículas individuais, sendo dessa maneira sua textura associada com a da gordura. Quando o substituto de gordura é apenas a proteína microparticulada, que é uma simples modificação física de sua estrutura, este é considerado GRAS pela FDA (LIMA; NASSU, 1996).

Os substitutos de gorduras a base de proteínas são indicados nas formulações de sobremesas, iogurte, queijos, sorvetes, maionese, margarinas e molhos (CÂNDIDO, 1996).

As proteínas microparticuladas resultam da agregação física de moléculas protéicas e não de interações químicas. Sendo assim, são mantidas a seqüência de aminoácidos e a conformação tridimensional da proteína. Desta forma, mantida a integridade química, são preservadas suas qualidades nutricionais. Proteínas de vários alimentos podem originar micropartículas, mas as mais utilizadas são as do leite e dos ovos. Um exemplo é o produto Simplesse ${ }^{\mathbb{R}}$ que foi desenvolvido à base de proteína de ovo e leite. Ele apresenta sabor suave e agradável e mascara o sabor residual de agentes de corpo, gomas e outros espessantes (LUCCA, 1994).

As aplicações do Simplesse $\mathbb{B}$ estão limitadas a produtos que não serão processados a temperaturas muito elevadas, como frituras ou assamentos prolongados. O calor excessivo faz com que ocorra gelatinização e o produto perde as características que o assemelham à gordura. Todavia, este substituto pode ser utilizado em produtos que serão submetidos a pasteurização (SETSER, 1992).

De acordo com Dusbury (1991), o Simplesse ${ }^{\circledR}$ pode ser empregado em sorvetes, iogurtes, temperos para saladas, maionese, margarina, sobremesas geladas, queijo e requeijão, coalhadas, coberturas para bolos, sopas, molhos, pudins, patês e pastas, tortas e produtos de panificação.

Dyminski et al. (2000) realizaram pesquisa para verificar as características físicoquímicas de mousse de maracujá elaborado com substitutos de gorduras. Os ingredientes utilizados na formulação do mousse padrão neste estudo foram: leite evaporado; gelatina em pó sem sabor, suco concentrado de maracujá, açúcar de cana, água deionizada e creme de leite.

No preparo do mousse padrão foi utilizado como fonte de gordura, o creme de leite integral contendo $24,95 \%$ de lipídios. Esta fonte tradicional de gordura foi substituída por uma polidextrose (Litesse-PFIZER $®$ ), por uma proteína derivada do leite (Dairy-Lo 
PFIZER ${ }^{\circledR}$ ) e por uma proteína microparticulada (Simplesse Dry 100NUTRASWEET®). Empregaram-se a proteína microparticulada e a polidextrose isoladamente e nas seguintes combinações: proteína microparticulada / polidextrose, proteína derivada do leite/ polidextrose e proteína derivada do leite / polidextrose / proteína microparticularizada. As características do aspecto e da forma das mousses formuladas com substituto de gordura foram comparadas com o padrão.

Segundo os resultados, as mousses de maracujá formuladas com substitutos de gordura alcançaram redução média de 40,5\% no valor energético e de 93,6\% no teor de gordura, comparativamente à mousse padrão elaborado com creme de leite integral.

As mousses formuladas com substituto da gordura tradicional foram consideradas, tanto em relação ao valor energético quanto ao teor de gordura, como produtos "light", podendo ser classificados como "valor calórico e teor total de lipídios reduzidos".

Observou-se, principalmente, o aspecto geral de forma visual do produto elaborado com combinações de substitutos de gordura. Constatou-se que o uso de um único elemento, a proteína microparticulada (PM) gerou no produto final teor de lipídios de 1,07 g/100 g. Este valor foi o maior obtido com os substitutos de gordura propostos e o que mais se aproximou do mousse tradicional (11,12 g /100 g de lipídios) com relação ao seu aspecto ou forma. Esta formulação também foi a que mais se aproximou do valor médio obtido para a redução do valor energético, pois no mousse elaborado com PM obteve-se 41,81\% e a média foi de $40,5 \%$.

Portanto, foi verificado nesta pesquisa que os produtos elaborados são adequados para serem consumidos por pessoas preocupadas com a saúde e/ou obesas (DYMINSKI et al., 2000).

Nabeshima et al (2001) avaliaram o efeito de substituto de gordura (Simplesse $® 100$ ) e de substituto de sacarose (Litesse ${ }^{\circledR}$ ) nas propriedades físicas de sorvete de baunilha, e compararam com os produtos de sorvete convencional, contendo gordura e açúcar. Foram avaliados o pH das misturas, a densidade aparente (medida de ar incorporado ao sorvete após o batimento) e a redução calórica e de gordura de sete amostras formuladas.

Os componentes dos sorvetes elaborados com substitutos de gordura distinguiram-se do sorvete controle ou padrão pela substituição total da sacarose por edulcorantes (mistura de $0,015 \mathrm{p} / \mathrm{p}$ aspartame e $0,015 \mathrm{p} / \mathrm{p}$ acessulfame k) e substituto de sacarose, Litesse ${ }^{\circledR}(6,8$ ou $10 \%$ da formulação). A redução da gordura de $5 \mathrm{p} / \mathrm{p}$ para $2 \mathrm{p} / \mathrm{p}$ foi compensada pela adição de substituto de gordura, Simplesse $\mathbb{R} 100$ (3, 4 ou 5\% da formulação). Os produtos Litesse $\mathbb{R}$ e 
Simplesse $\mathbb{R} 100$ foram adicionados em porcentagens definidas em ensaios preliminares e com base nas recomendações do fabricante.

$\mathrm{O}$ pH das misturas variou de 6,47 a 6,56 mostrando-se de acordo com os valores encontrados na literatura.

Verificou-se que os valores de densidade aparente para todos os tratamentos foram menores do que o valor encontrado para o controle. Em todas as amostras houve redução calórica de $26,0 \%$ a $31,4 \%$ em relação à fórmula padrão e redução de gordura de $60 \%$, podendo ser classificado como alimento de "baixo teor de gordura".

Teores mais baixos de Simplesse ${ }^{\circledR}$ parecem acelerar a velocidade de derretimento, enquanto que teores maiores tendem a retardar este processo. A combinação de $4 \%$ de

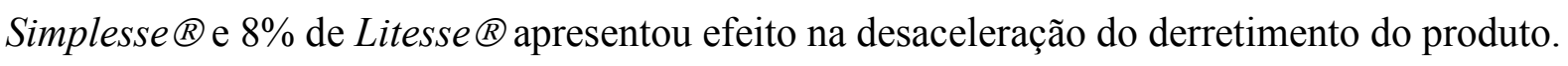

Considerando os teores de Simplesse ${ }^{\circledR}$ e de Litesse ${ }^{\circledR}$ estudados pode-se concluir que para se obter sorvete com menor densidade aparente deve-se trabalhar com concentrações

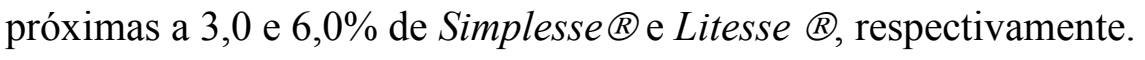

As proteínas modificadas texturizadas pertencem a uma classe de substituto de gordura composta por albumina de ovo e proteína do leite (Traiblazer $®)$. Este produto é elaborado a partir de uma mistura de clara de ovo desidratada e concentrado protéico de soro ou leite desnatado, em uma matriz contendo goma como adjunto (especialmente a goma xantana). A matriz é formada por submeter à mistura a uma solução aquosa cujo pH e temperatura de ebulição são cuidadosamente controlados até formar uma concentração de proteínas fibrosas. Este produto é muito utilizado como agente texturizante em sobremesas geladas e como substitutos de carnes (CÂNDIDO, 1996).

As proteínas derivadas do leite consistem de duas frações principais: a caseína e as proteínas do soro ( $\alpha$ lactalbumina, $\beta$ lactoglobulina). Um produto muito utilizado em

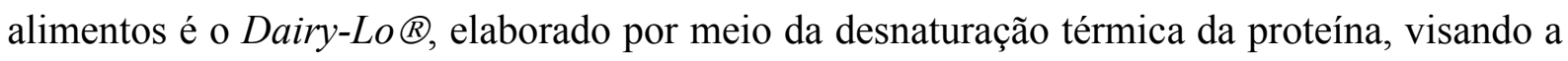
maximizar sua funcionalidade. A desnaturação térmica controlada tem como resultado o desenovelamento da proteína, expondo regiões hidrofóbicas da cadeia polipeptídica e conferindo caráter anfifílico (LUCCA, 1994).

O aumento do caráter anfifílico melhora a capacidade de emulsificação da proteína. A auto-agregação e o desenovelamento da proteína aumentam a interação com a água, o que melhora a textura de alimentos com baixo teor de gordura. Devido à formação de agregados protéicos, suas soluções ácidas ou neutras são opacas, o que confere aparência cremosa ao 
alimento. São muito utilizadas em preparo de queijos, iogurtes, cremes, molhos e produtos de panificação (CÂNDIDO, 1996).

Soares et al. (2002) elaboraram um processamento de requeijão em barra com teor reduzido de gordura, utilizando concentrado protéico de soro como substituto da gordura, e avaliaram suas características físico-químicas $(\mathrm{pH}$, acidez, umidade, teor de gordura, teor de proteína e teor de cinzas).

O leite foi desnatado para $0,5 \%$ de gordura, pasteurizado a $65^{\circ} \mathrm{C}$ por 30 minutos. Para o grupo-controle, foi utilizado o creme de leite fresco, com teor de gordura tradicional para a fabricação do requeijão em barra, que variou de 52 a $56 \%$ de gordura. Para o requeijão fabricado com teor reduzido de gordura, o creme de leite foi padronizado para 33 a $35 \%$ de gordura.

Foram avaliados quatro tratamentos: tratamento 1 ou grupo-controle (teor normal de gordura) e tratamentos 2,3 e 4, com redução de $30 \%$ de gordura e adição de $0,2,1,0$ e 2,0\% de concentrado protéico de soro (ALACEN" ${ }^{\mathrm{TM}} 131$ ), com $80 \mathrm{~g}$ de proteína/100g do produto.

Neste estudo não foram observados diferenças nas características físico-químicas dos tratamentos em relação ao grupo-controle, exceto para o teor de gordura resultando em produto adequado ao Padrão de Identidade e Qualidade de requeijão e, barra (BRASIL, 1997) com teor reduzido de lipídeos.

Segundo Cândido \& Campos (1995), os produtos de soro, sobretudo o concentrado protéico de soro, são particularmente indicados para produtos lácteos não tradicionais, como os de teor reduzido de gordura, por possuírem propriedades funcionais, como a capacidade de formação de gel, a correta viscosidade, o poder emulsificante, a capacidade de retenção de água e a capacidade espumante, que conferem uma série de benefícios estruturais e nutricionais ao produto final. A utilização do uso do concentrado protéico de soro - CPS diminui a sinérese, melhora a textura e altera a viscosidade do produto final, como em queijos e outros produtos lácteos.

As proteínas do leite (até 3,5\% de caseinato) são de particular interesse em termos de funcionalidade, especialmente no que se referem às propriedades emulsificantes e formação de gel, mas também podem levar ao aumento da coesividade, dureza e elasticidade (COLMENERO, 1996). Para melhorar o seu desempenho como substituto da gordura, as proteínas do leite podem ser misturadas com hidrocolóides, como a goma xantana, a qual, devido à estabilidade da viscosidade a altas temperaturas e pseudoplasticidade, confere a característica cremosa ao produto (FIGUEIREDO et al., 2001). 
Figueiredo et al. (2001) discutiram o efeito da combinação de concentrado protéico de soro de leite e goma xantana sobre as propriedades físicas e aceitação das salsichas tipo Viena.

Três diferentes formulações foram elaboradas: padrão, com 22\% de toucinho (P); substituição total do toucinho pelos substitutos de gordura (P1) e substituição parcial de $50 \%$ (P2).

Os resultados mostraram que o teor de umidade foi maior para substituição total do toucinho e substituição parcial. Os teores de lipídeos, proteínas e cinzas apresentaram diferenças significativas entre os produtos.

O valor calórico foi reduzido em $39 \%$ no produto P1. A adição de substitutos de gordura reduziu a atividade de água. O teste sensorial de preferência (sabor e textura) indicou que a substituição parcial da gordura resulta em produtos aceitáveis quando comparados com o padrão.

Concluiu-se, então, que a adição da mistura concentrado protéico de soro de leitegoma xantana, como substitutos da gordura animal em salsichas tipo Viena, resultou em produtos com redução do valor calórico, os quais se mantiveram estáveis por 28 dias com relação às propriedades físicas avaliadas.

A substituição total da gordura por essa mistura não é aconselhável do ponto de vista sensorial, pois torna os produtos mais endurecidos e um sabor não tão agradável quanto o dos convencionais. Na substituição parcial torna-se possível, uma vez que sensorialmente estes produtos não apresentaram um valor depreciativo (FIGUEIREDO et al., 2001).

A soja e seus derivados têm recebido atenção dos pesquisadores, principalmente devido ao teor e qualidade de sua proteína, sendo considerada, entre os vegetais, o melhor substituto de produtos de origem animal. Além disso, a soja é importante fonte de outros compostos, como fibras, oligossacarídeos com potencial prebiótico, como rafinose e estaquiose, vitaminas e minerais (ANGELIS, 2002).

O isolado protéico de soja apresenta mais de $90 \%$ de proteína. Não deve ser confundido com a farinha de soja (50\% de proteína), que é o resíduo moído da extração do óleo ou com concentrado protéico ( $70 \%$ de proteína) que contém carboidratos residuais como estaquiose e rafinose (GIESE, 1992).

O concentrado protéico de soja possui propriedades funcionais de emulsificação, geleificação e melhora de textura. Além da importância nutricional em função do perfil de aminoácidos, o concentrado protéico de soja contém $22 \%$ de fibras alimentares, que atuam diminuindo os níveis de colesterol e a incidência de câncer colônico (RAKES, 1992). 
Sua aplicação principal é na elaboração de produtos cárneos de baixo teor de gordura. Nestes, a farinha de soja e o concentrado protéico de soja podem ser utilizados em concentração de até $3,5 \%$ como ligantes. O uso do isolado protéico é limitado a $2 \%$. Pode, também, ser utilizado no preparo de bebidas, produtos crocantes e suplementos dietéticos (DUXBURY, 1991).

A empresa Protein Technologies International colocou no mercado mais de 30

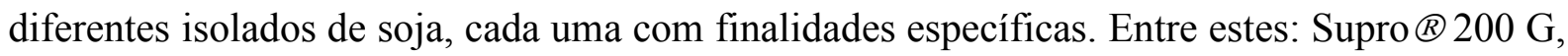
Pro Plus $\AA$, Supro Plus $\AA$, Supro $\AA$ 500. São utilizados como substitutos de gorduras principalmente em biscoitos e em produtos cárneos, nos quais é possível obter redução calórica de 57\% e 44\%, respectivamente (CÂNDIDO, 1996).

Yazici et al. (1997) desenvolveram iogurte de soja, formulado a partir de farinha de soja suplementada com isolado protéico de soja, xarope de milho, glucose, sacarose e lactogluconato de cálcio, visando à melhoria no teor deste mineral no iogurte. A composição química do produto foi de 5,4\% de proteínas, $6,6 \%$ de carboidratos, 1,5\% de lipídios, 1,6\% de cinzas e o teor de cálcio foi de $190 \mathrm{mg} / 100 \mathrm{~g}$.

Lee et al. (1990) avaliaram o teor protéico de iogurte de soja suplementado com concentrado protéico de soro ou leite em pó desengordurado. O produto suplementado com concentrado protéico apresentou $8,12 \%$ de proteínas, enquanto o suplementado com leite em pó desengordurado apresentou 7,28\%, sendo que ambos obtiveram maior concentração protéica, se comparados ao iogurte de soja elaborado nesse trabalho.

Produtos cárneos emulsificados, como salsichas, salsichões, mortadelas e patês, entre outros, têm níveis elevados de gordura. Estes produtos, contudo, oferecem grandes oportunidades para redução calórica por meio da elaboração de novas formulações, utilizando substitutos de gordura (KEETON, 1994).

O patê é um produto industrializado que contém principalmente carnes, gorduras e especiarias, cuja massa tem aspecto fino. Pode apresentar em sua formulação até $32 \%$ de gorduras totais (BRASIL, 2000), nível considerado elevado, especialmente quanto às gorduras saturadas. A redução do teor de gorduras desse produto seria desejável, uma vez que contribuiria para a redução de ácidos graxos saturados e, consequentemente, do teor de colesterol, obtendo, assim, um produto mais saudável.

O desenvolvimento de emulsões cárneas com baixo teor de gordura não consiste apenas na simples retirada desse ingrediente, dependendo, assim, de alguns fatores essenciais, tais como: a quantidade de gordura que pode ser removida do sistema, a natureza do produto a ser formulado e o tipo de processamento empregado. 
Uma das características que podem ser bastante afetadas pela retirada de gordura em uma emulsão cárnea são as propriedades ligantes, uma vez que esses fatores estão diretamente relacionados à formação de emulsões estáveis e, conseqüentemente, à qualidade da massa crua (CARBALLO et al., 1995).

O emprego das proteínas como substitutos de gordura em produtos cárneos têm sido sugeridos por diversos autores, uma vez que apresenta vantagens tanto do ponto de vista nutricional, quanto do calórico, quando o interesse está voltado para dietas especiais com redução de calorias (KEETON, 1994).

De acordo com vários relatos, o sangue é um dos mais importantes subprodutos do abate em frigoríficos e é uma fonte potencial de proteínas. Devido à sua riqueza em proteínas ( $17 \% \mathrm{p} / \mathrm{p}$ em média) é muito utilizado em diversos países na alimentação humana, em produtos como sopas, molhos e pães (AUVINEN, 1992).

As quantidades de sangue anualmente disponíveis são muito elevadas, sendo no Brasil a produção aproximada em 90 milhões de litros. Porém, somente uma pequena parte é empregada em produtos alimentícios, sendo a maior parte destinada à elaboração de fertilizante e ração para animais. Por esse motivo, o emprego do sangue bovino poderia ser de grande utilidade na indústria alimentícia, pois além de melhorar o valor nutritivo, pode contribuir significativamente para a redução de problemas de poluição ambiental (ORNELLAS et al., 2000).

No Brasil, somente uma pequena quantidade de sangue bovino é utilizada para esse fim, mas alguns estudos têm sido realizados com o objetivo de encontrar um melhor aproveitamento para esse produto. Dessa forma, a globina e o plasma obtidos do sangue bovino poderiam ser incorporados em alimentos variados, pois além de apresentarem boas propriedades funcionais, contêm todos os aminoácidos essenciais para a nutrição humana. (ORNELLAS et al., 2000).

Viana et al (2003) avaliaram o efeito da substituição parcial da gordura pela globina e pelo plasma bovino sobre a qualidade do patê de presunto. Para isso, foram preparadas amostras controle e outras nas quais foram feitas substituições de 38,2\% da gordura suína (globina e o plasma). Foram avaliados na massa crua o teor de proteínas sal-solúveis e as propriedades ligantes, tais como a capacidade de retenção de água e a estabilidade da massa crua.

O sangue foi obtido de animais abatidos em frigorífico sob inspeção federal, sendo coletado diretamente da ferida de sangria, em frascos contendo quantidade necessária de anticoagulante. 
No momento da coleta, evitou-se o contato entre a vasilha coletora e a pele do animal. Após liberado pela inspeção federal, o sangue foi centrifugado para separação das células vermelhas (hemáceas) e do plasma. As células vermelhas foram armazenadas sob refrigeração, até o momento da extração da globina bovina, por um período máximo de $24 \mathrm{~h}$. O plasma foi transferido para frascos de vidro e mantido a $-18^{\circ} \mathrm{C}$, até o momento de sua utilização (VIANA et al., 2003).

Neste estudo da substituição parcial da gordura pela globina e pelo plasma bovino sobre a qualidade do patê de presunto, foram preparados dois tipos de patê, sendo uma formulação controle com o teor de gordura total (toucinho) de $26,2 \%$ e outra com substituição de $10 \%$ do toucinho $(38,2 \%$ da gordura total) por proteína, utilizando um dos três substitutos de gordura propostos: $10 \%$ de globina (GL), 10\% de plasma (PL), 5\% de globina e 5\% de plasma (GP). Essas substituições resultaram em três formulações de patê, denominadas de PGL, PPL e PGP, respectivamente.

A incorporação de globina bovina resultou em valores de proteína sal - solúveis similares aos do controle. O uso do plasma bovino, isoladamente ou em associação com globina bovina, promoveu um aumento significativo de proteína sal - solúvel quando comparado ao controle. Resultados similares também foram observados para a estabilidade da massa crua, em que a incorporação da globina bovina resultou em maiores valores $(p<0,05)$ do que nas formulações contendo plasma ou globina. Em relação à capacidade de retenção de água, todas as formulações estudadas foram inferiores ao controle, sendo os melhores resultados obtidos para globina bovina e os piores quando foi utilizado plasma bovino.

Segundo os pesquisadores, observaram-se diferenças significativas quanto ao teor de proteínas sal - solúvel entre os tratamentos estudados. Ao comparar os resultados obtidos para os patês nos quais foram empregados substitutos de gordura com os do controle (sem substitutos de gordura), verifica-se que a incorporação de globina não exerceu qualquer influência sobre o teor de proteínas sal - solúveis, resultando em valores similares $(p<0,05)$ a PCO.

Por outro lado, a adição de plasma isoladamente e em associação com a globina elevou o teor de proteínas sal-solúveis, podendo-se atribuir esse resultado à não-emulsificação dessas proteínas que, conseqüentemente, foram perdidas durante o processamento. Com relação à utilização de GL como substituto de gordura, pode ser observado que, se por um lado houve uma redução da capacidade da massa crua em reter água, por outro, essa proteína foi capaz de elevar a sua estabilidade, quando comparada à formulação controle (PCO). 
O resultado obtido para estabilidade da massa crua poderia ser explicado pelo fato de que a GL, por ser uma proteína isolada adicionada ao patê na forma de pasta e que apresenta boas propriedades emulsionantes (SILVA et al., 2000), teria uma participação efetiva na estrutura da rede protéica durante a formação da emulsão, contribuindo, assim, para manter a sua estabilidade.

Esse efeito da globina sobre a estabilidade da massa crua poderia também estar associado ao resultado das proteínas sal-solúveis, na medida em que a adição dessa proteína ao patê de presunto não alterou o teor desse parâmetro, mas elevou o nível da estabilidade da massa crua, indicando que grande parte da proteína adicionada participou da formação da emulsão e não foi perdida na forma de proteína sal-solúvel.

Concluiu-se, neste estudo, que a incorporação da globina foi ligeiramente mais vantajosa e mais eficiente em relação à do plasma, isoladamente ou em associação à globina, para a qualidade do patê de presunto, uma vez que não alterou o teor de proteínas sal-solúveis e elevou a estabilidade da massa crua das amostras.

\subsubsection{Substitutos de gorduras a base de carboidratos}

A maioria dos substitutos de gorduras pertence a este grupo. Os carboidratos e produtos a base de carboidratos têm sido usados para substituir total ou parcialmente (de 50 a $100 \%$ ) óleos e gorduras em uma grande variedade de alimentos por mais de uma década. Carboidratos fornecem $4 \mathrm{kcal} / \mathrm{g}$, mas como os substitutos baseados nestes são normalmente utilizados em soluções $25 \%$ ou $50 \%$ em formulações de alimentos, tem-se somente 1 ou 2 $\mathrm{kcal} / \mathrm{g}$ no produto final (LIMA; NASSU, 1996).

Neste grupo encontram-se maltodextrinas, amidos modificados, polidextrose, gomas, pectina e celulose como são apresentados no Tabela 2.

Tabela 2: Tipos de substitutos de gorduras a base de carboidratos

\begin{tabular}{|l|l|l|l|}
\hline Tipos de carboidrato & \multicolumn{1}{|c|}{ Produtos } & \multicolumn{1}{c|}{ Fonte } & \multicolumn{1}{c|}{ Aplicação } \\
\hline \multirow{3}{*}{ Polidextrose } & & - Glucose, & - Balas de Goma \\
& - Litesse $\Theta$, & - Sorbitol & - Gelatina \\
& - StaLife $\Theta$ & - Ácido cítrico & - Panificação \\
& & & - Coberturas \\
\hline
\end{tabular}


Tabela 2: Tipos de substitutos de gorduras a base de carboidratos (continuação)

\begin{tabular}{|c|c|c|c|}
\hline Tipos de carboidrato & Produtos & Fonte & Aplicação \\
\hline $\begin{array}{l}\text { Amido microcristalinos } \\
\text { e modificados }\end{array}$ & $\begin{array}{l}\text { - Accu-Gel } \\
\text { - OptaGrade } \\
\text { - Stellar }{ }^{\circledR} \\
\text { - Novelóse } \\
\text {-CrystaLean }\end{array}$ & $\begin{array}{l}\text { - Arroz } \\
\text { - Batata } \\
\text { - Tapioca } \\
\text { - Milho } \\
\text { - Aveia } \\
\text { - Trigo }\end{array}$ & $\begin{array}{l}\text { - Produtos lácteos } \\
\text { - Molhos } \\
\text { - Sorvetes } \\
\text { - Sobremesas geladas }\end{array}$ \\
\hline Maltodextrina & 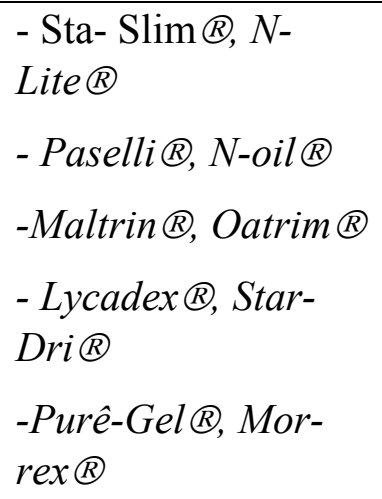 & - Amido de milho & $\begin{array}{l}\text { - Produtos de panificação } \\
\text { - Maionese, queijo } \\
\text { - Sobremesa } \\
\text { - Tortas, bolos, temperos }\end{array}$ \\
\hline Pectina & - Slendid $\mathbb{R}$ & $\begin{array}{l}\text { - Albedo dos } \\
\text { cítricos } \\
\text { - Maçã, vegetais }\end{array}$ & $\begin{array}{l}\text { - Molhos, queijos } \\
\text { - Produtos Cárneos } \\
\text { - Bolos, tortas. }\end{array}$ \\
\hline Inulina & $\begin{array}{l}\text { Fibruline }{ }^{\circledR} \\
\text { Rafticreming }{ }^{\circledR} \\
\text { Raftiline }{ }^{\circledR}\end{array}$ & $\begin{array}{l}\text { - Alho } \\
\text { - Chicória } \\
\text { - Alcachofra } \\
\text { - Cereais } \\
\text { - Cebola } \\
\text { - Aspargos }\end{array}$ & $\begin{array}{l}\text { - Panificação } \\
\text { - Sorvetes } \\
\text { - Produtos lácteos }\end{array}$ \\
\hline $\begin{array}{l}\text { Gomas: } \\
\text { Carragena } \\
\text { Guar } \\
\text { Xantana } \\
\text { Arábica } \\
\text { Gelana }\end{array}$ & $\begin{array}{l}\text { - CaraLite }{ }^{\circledR} \\
\text { - Carafat } \AA \\
\text { - Marine Colloids } \AA \\
\text { - Nutricol } \AA \\
\text { - Fibregnum } \AA\end{array}$ & $\begin{array}{l}\text { - Extrato de algas } \\
\text { marinhas } \\
\text { - Extratos de } \\
\text { sementes } \\
\text { - Exudatos vegetais } \\
\text { - Microrganismo } \\
\text { - Celuloses } \\
\text { quimicamente } \\
\text { momodificadas. }\end{array}$ & $\begin{array}{l}\text { - Produtos cárneos } \\
\text { - Geléias } \\
\text { - Chocolates } \\
\text { - Pudins } \\
\text { - Manteiga, margarina } \\
\text { - -Sobremesas geladas }\end{array}$ \\
\hline
\end{tabular}


Tabela 2: Tipos de substitutos de gorduras a base de carboidratos (continuação)

\begin{tabular}{|c|c|c|c|}
\hline Tipos de carboidrato & Produtos & Fonte & Aplicação \\
\hline Celulose & 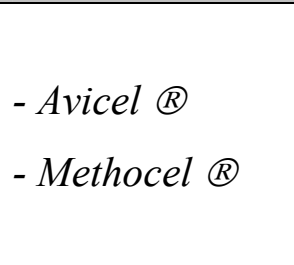 & $\begin{array}{l}\text { Componentes de } \\
\text { vegetais }\end{array}$ & $\begin{array}{l}\text { - Pães, Bolos } \\
\text { - Molhos e queijos } \\
\text { - Alimentos congelados } \\
\text { - Bebidas, etc. }\end{array}$ \\
\hline
\end{tabular}

Fonte: CÂNDIDO, 1996

Os substitutos compostos por carboidratos são termoestáveis e podem ser utilizados em produtos de panificação. Podem ser utilizadas associações de vários carboidratos para conferir a textura adequada. Em temperos para saladas, amidos modificados, maltodextrinas e celulose modificada apresentam as propriedades ideais.

A atividade da água em um produto determina sua estabilidade microbiológica. A adição de substitutos de gorduras a base de carboidratos promove redução da atividade de água, dada a higroscopicidade das moléculas. A utilização de agentes antimicrobianos, agentes de corpo (polidextrose, xaropes, maltodextrinas) que diminuem a atividade de água e/ou o processamento asséptico permitem a melhor conservação dos produtos (CÂNDIDO, 1996).

A polidextrose é um polímero de moléculas de glucose unidas por ligações de sorbitol e ácido cítrico. O ácido cítrico atua como catalisador e o sorbitol como agente plastificante. Estão disponíveis vários tipos de produtos e um deles é a Litesse $\mathbb{R}$, caracterizada por ser um pó amorfo branco amarelado. Não apresenta sabor doce e em alguns casos poder ser vantajosa, pois permite inúmeros produtos com baixo teor de açúcares e gorduras (KOPCHIK, 1993). É um agente de volume, que pode substituir parcialmente açúcares e gorduras, desempenhando as funções de espessante, umectante, auxiliar de formulação e modificador de textura. Pode auxiliar no controle da atividade de água, o que preserva o frescor e prolonga a vida de prateleira de muitos produtos. Apresenta alta solubilidade em água (ANDERSON, 1990).

Balas de goma, "marshmallows", gomas de mascar, pudins, misturas desidratadas de pré-preparo para uma série de produtos, gelatinas, produtos de panificação, molhos para saladas e coberturas são exemplos de produtos que podem ser elaborados e aplicados com a polidextrose (CÂNDIDO, 1996). 
Sivieri e Oliveira (2002) avaliaram a vida de prateleira de sete bebidas lácteas preparadas com Litesse ${ }^{\circledR}$ e Dairy-lo ${ }^{\circledR}$ (substitutos de gorduras) e verificaram que o uso desses substitutos nas bebidas obteve o melhor sabor, consistência e aparência após 28 dias de armazenamento (todas foram classificadas como boas). Os autores verificaram que não houve influência no comportamento físico-químico das bebidas estudadas.

O iogurte foi elaborado utilizando leite desnatado pasteurizado, adicionado dos "fat replacers", em concentrações definidas de acordo com o delineamento experimental. Após a elaboração do iogurte e do soro, estes foram submetidos à determinação de sólidos totais com vistas à padronização da bebida em cerca de $10 \%$ de sólidos totais. As bebidas lácteas foram e armazenadas a $5^{\circ} \mathrm{C}$ durante 28 dias.

$\mathrm{O}$ leite e o soro foram submetidos às análises de valor de $\mathrm{pH}$, teores de acidez, densidade, gordura e sólidos totais. As bebidas lácteas foram submetidas às análises de valor de $\mathrm{pH}$ e teor de acidez e de tirosina ao $0,7,14,21$ e 28 dias de armazenamento.

As bebidas lácteas foram submetidas à análise sensorial de aparência, consistência e sabor no dia do processamento aos 28 dias de armazenamento a $5^{\circ} \mathrm{C}$ utilizando escala de 5 pontos: péssimo; ruim; regular; bom; ótimo.

A estimativa da vida-de-prateleira foi efetivada estudando-se a taxa de incremento ou de decaimento das respostas valor de $\mathrm{pH}$, teor de acidez e teor de tirosina, em função do tempo de armazenamento.

Após 28 dias de armazenamento as bebidas lácteas dos experimentos foram consideradas de ruim a razoável. Após este prazo, os autores verificaram que os iogurtes apresentaram-se mais ácidos e com sabor amargo. O desenvolvimento do sabor amargo foi devido à atividade proteolítica do Lactobacillus bulgaricus.

Portanto, pode-se concluir desse experimento que a utilização de diferentes concentrações de Litesse e Dairy-lo não influenciou o comportamento físico-químico e a aparência das bebidas lácteas estudadas.

O sabor foi o atributo mais afetado com o armazenamento, em função disto, pôde-se estabelecer o tempo ideal para a vida-de-prateleira de 28 dias das bebidas lácteas estudadas, indicando a viabilidade da utilização do Litesse e Dairy-lo em formulações de bebidas lácteas.

O amido é o produto amiláceo extraído das partes comestíveis dos vegetais (sementes, frutos, etc). Ele pode ser classificado em amido microcristalino, amido modificado e maltodextrina. Suas aplicações nas indústrias de alimentos relacionam-se com suas propriedades: espessante, geleificante, modificador de textura e para elaboração de xarope de 
glucose. Entre as principais vantagens do emprego do amido está o baixo custo, disponibilidade e facilidade de armazenamento e manipulação. As desvantagens são a baixas estabilidades a gelo-degelo, a ácidos, a calor e a cisalhamento (LUCCA; TEPPER, 1994).

O amido, para atuar como substituto de gorduras deve sofrer modificações, visando a apresentar comportamento mais próximo dos lipídeos (amidos modificados). Elas podem ser efetuadas por métodos químicos, físicos ou enzimáticos. Estas modificações melhoram a estabilidade, cremosidade e retenção da umidade dos amidos. As principais aplicações dos amidos modificados incluem as carnes, molhos para saladas, condimentos, recheios, sobremesa gelada e produtos lácteos (BOURSIER, 1994).

Os amidos modificados possuem características funcionais similares às da gordura obtidos por meio de tratamentos ácido, enzimático e/ou físico ou por substituição química. Amidos hidrolisados em altas concentrações (25-50\%) e com valores de dextrose equivalente (DE) inferiores a 20 podem ser utilizados como substitutos de gordura, proporcionando características funcionais e sensoriais similares às da gordura (LUCCA; TEPPER, 1994).

O amido microcristalino (utilizado no produto Stellar $(\mathbb{R})$ é obtido do amido de milho produzido por uma hidrólise ácida controlada. O tratamento despolimeriza a estrutura amorfa da amilopectina. O produto Stellar ${ }^{\circledR}$ é desidratado e vendido como pó branco. O produto proporciona estrutura cremosa, sistemas alimentares estáveis, sabor suave, reduz o envelhecimento em produtos panificados e estende a vida de prateleira. Pode ser utilizado em alimentos que serão submetidos a processamento térmico moderado e resiste a variações texturais a temperaturas de congelamento (BEST, 1992).

Zambrano e Camargo (1999) estudaram o efeito da interação do tempo (3; 6; 9 horas) e da concentração de ácido clorídrico $(1,5 ; 3,0 ; 4,5 \%)$ na hidrólise do amido de mandioca nativo em reação à temperatura constante $\left(52^{\circ} \mathrm{C}\right)$, visando obter géis com características funcionais e sensoriais similares à gordura.

A hidrólise foi avaliada por meio dos parâmetros dextrose equivalente (DE), formação e termorreversibilidade do gel, força dos géis, viscosidade a $550^{\circ} \mathrm{C}$ e cor, os quais foram comparados com os dos produtos amiláceos comerciais usados como substitutos de gordura, Paselli SA2 e N-lite B.

O $N$-lite $\&$ B é uma maltodextrina derivada de amido de milho ceroso, termoestável e com sabor suave. É resistente a ciclos de gelo-degelo e indicada para produtos de panificação. Pode substituir até $50 \%$ da gordura (100\% em folhados), melhorando características de 
plasticidade e lubricidade. É estável ao aquecimento e retém umidade e prolonga a vida de prateleira (CÂNDIDO, 1996).

O Paselli ${ }^{\circledR} S A 2$ é um amido de batata modificado enzimaticamente. Uma solução concentrada desse produto sob condições apropriadas forma um gel macio, com textura de gordura e sabor suave. Imediatamente após a dissolução a solução tem baixa viscosidade, mas a gelatinização ocorre após poucas horas. A força do gel do produto é influenciada pelo $\mathrm{pH}$ e temperatura na qual o amido é hidratado. Exposição prolongada a altas temperaturas reduz sua capacidade geleificante (CÂNDIDO, 1996).

Pode substituir óleos e gorduras em uma série de produtos: molhos de vários tipos, glacês, temperos para saladas, maionese, sobremesas geladas e produtos panificáveis, permitindo redução de até $50 \%$ das gorduras.

Os valores (dextrose equivalente) DE aumentaram com os incrementos do tempo de hidrólise e da concentração de ácido, sendo maior a influência da concentração de ácido nos tempos de 6 e 9 horas. Por outro lado, os valores da força dos géis diminuíram com o incremento no tempo de hidrólise e na concentração de ácido. O maior efeito ocorreu com o incremento na concentração de ácido, com 3 horas de reação.

Os valores da força dos amidos hidrolisados com $3 \%$ de $\mathrm{HCl}$ durante 3 e 6 horas, da viscosidade dos amidos hidrolisados com 1,5\% e 3,0\% de $\mathrm{HCl}$ por um período de 9 e 3 horas, respectivamente, e o parâmetro de cor do amido tratado com 3,0\% de $\mathrm{HCl}$ por 6 horas foram estatisticamente iguais aos do produto comercial Paselli SA2. Com base nas características de formação e termorreversibilidade do gel foram selecionados 4 tratamentos: N0 $3(1,5 \% \mathrm{HCl}$; 3 horas), N0 4 (3,0\% HCl; 3 horas), N0 5 (3,0\% HCl; 6 horas) e N0 7 (4,5\% HCl; 3 horas).

Neste experimento pode-se observar que a hidrólise ácida do amido de mandioca nos tratamentos: $1,5 \%$ de $\mathrm{HCl} / 6$ e 9 horas, 3,0\% de $\mathrm{HCl} / 3$ e 6 horas e 4,5\% de $\mathrm{HCl} / 3$, horas produziu hidrolisados com valores de $\mathrm{DE}=2,92 ; 3,24 ; 4,02 ; 9,46$ e 8,34 respectivamente, os quais apresentaram as características de formação e termorreversibilidade do gel, parâmetros considerados fundamentais na obtenção de substitutos de gordura a partir de amido.

Segundo o autor, as condições estabelecidas neste estudo foram importantes para futura aplicação no estabelecimento das variáveis e dos níveis de variação em estudos de otimização das condições de hidrólise ácida do amido de mandioca, para a obtenção de hidrolisados com características de substituto de gordura.

Em um outro estudo, Zambrano e Camargo (2001) avaliaram o amido de mandioca modificado em condições de temperatura $\left(47^{\circ} \mathrm{C}\right)$ em uma concentração de ácido $(3,5 \% \mathrm{HCl})$ e tempo de hidrólise (6 horas), em comparação com os substitutos de gordura comerciais 


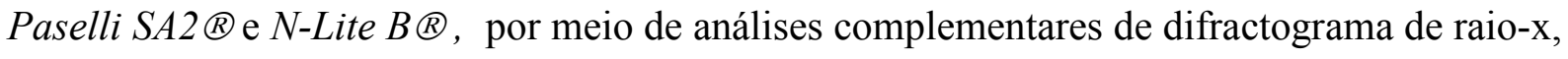
viscosidade intrínseca e microscopia ótica.

Os padrões de difração de raios-X ajudam na identificação de amidos naturais e no estudo da fração cristalina no grânulo de amido. O grânulo de amido nativo apresenta dois padrões de cristalinidade: padrão $\mathrm{A}$, característico de amido de cereais e suas variedades cerosas (ROSENTHAL, 1974) e padrão B, observado em amido de tubérculos, raízes e frutas.

Quando uma dispersão aquosa de amido é aquecida progressivamente, ocorre o início da fusão das regiões cristalinas do grânulo. Se o aquecimento continua, o amido se hidrata e incha de forma irreversível, a viscosidade aumenta até o máximo e a dispersão se torna transparente. Este fenômeno, denominado gelatinização, provoca mudanças irreversíveis na estrutura do grânulo, perda de birrefringência e do difractograma de raio- x característico (BILIADERIS, 1991). Quando a dispersão de amido gelatinizado é esfriada, as moléculas de amilose se aproximam formando zonas cristalinas, com a conseqüente formação de um gel (retrogradação).

A viscosidade intrínseca é essencialmente uma medida da fricção interna ou resistência ao deslocamento de moléculas de alto peso molecular em solução e, quando determinada em uma série homóloga de um tipo único de moléculas, constitui um excelente critério de avaliação do tamanho molecular.

A viscosidade intrínseca tem sido usada como indicador do grau de hidrólise em amidos modificados por ácidos, diminuindo com a intensidade do tratamento (LEACH, 1963). Os amidos comuns são facilmente identificados através de microscopia com luz polarizada usada para determinar seu tamanho e forma (JANE et al., 1994). De acordo com sua origem, os grânulos de amido diferem entre si na forma, tamanho e outras características físicas.

Os autores verificaram, neste estudo, que apesar das condições de hidrólise ácida $\left(47^{\circ} \mathrm{C}, 3,5 \% \mathrm{HCl}\right.$ e 6 horas), o amido de mandioca nativo não provocou alteração na orientação molecular. Por outro lado, mostrou que o tratamento ácido do amido de mandioca provocou aumento da cristalinidade relativa, devido à erosão principalmente da parte amorfa do grânulo.

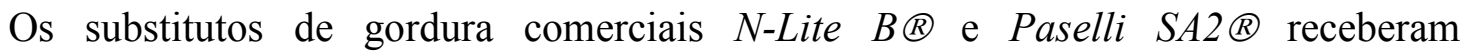
tratamentos que produziram mudanças na birrefringência e na cristalinidade. Os baixos valores da viscosidade intrínseca do amido de mandioca modificado, do $N$-Lite $B \mathbb{R}$ e do

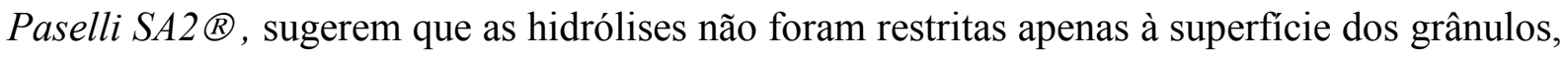


ocorrendo também na rede molecular do amido nativo de mandioca, de milho ceroso e de batata, respectivamente.

A diminuição do teor de gordura em produtos cárneos geralmente implica a redução de atributos de qualidade como maciez, suculência e rendimento (TROY et al., 1999).

Em outro trabalho, Seabra et al (2002) verificaram o efeito do uso da fécula de mandioca e da farinha de aveia como substitutos parciais da gordura ovina, sobre as características de qualidade de hambúrgueres formulados com este tipo de carne.

Os pesquisadores testaram 4 formulações à base de carne ovina limpa: testemunha sem gordura adicionada (F1), com 9,15\% de gordura ovina adicionada (F2), sem gordura adicionada e $2 \%$ de fécula de mandioca (F3) e sem gordura adicionada e $2 \%$ de farinha de aveia (F4). Foram avaliados durante o cozimento: composição centesimal, rendimento, encolhimento e capacidade de retenção de água, força de cisalhamento, cor e análise sensorial dos hambúrgueres.

Os produtos nos quais foram adicionados os substitutos de gordura (F3 e F4) apresentaram menor teor de gordura, antes e depois de cozidos, menor encolhimento, maior rendimento e capacidade de retenção de água do que os das formulações F1 e F2.

A força de cisalhamento e a intensidade de vermelho foram menores nos produtos aos quais foram adicionados os substitutos de gordura (F3 e F4) do que nos produtos sem substituição (F1 e F2). Não foram detectadas diferenças na aceitação global dos produtos com diferentes formulações.

Desta forma, concluiu-se que o uso de fécula de mandioca e farinha de aveia pode ser uma alternativa de substituição de gordura em produtos de carne ovina de baixo nível de gordura tipo hambúrguer.

O uso de fécula de mandioca, um produto amplamente disponível no mercado local, apresentou promissor em produtos cárneos, considerando que o amido dessa raiz tuberosa começa a gelatinizar na mesma temperatura em que a carne começa a cozer. Isto implica a necessidade de uma menor quantidade de amido de mandioca que de amidos de outro tipo para reter água e obter produtos suculentos (PSZCZOLA, 1999).

A aveia é um ingrediente básico em muitos produtos, incluindo aqueles com teor reduzido de gorduras ou de calorias e de alto teor de fibras. A farinha de aveia é um espessante que proporciona textura cremosa e macia. Os grânulos são pequenos e irregulares, e forma um gel elástico e estável. A proteína é de alto valor biológico e corresponde a 15 a $20 \%$, dependendo do cultivo. Indicado para o preparo de sobremesas, molhos, recheios e outros, a temperatura ambiente. É estável na elaboração de queijos macios pasteurizados, 
margarinas, temperos para saladas, molhos, maionese, tortas, bolos e em produtos de panificação ricos em fibras, especialmente porque não diminuem o volume dos assados como as outras gomas (BEST, 1992).

As vantagens de se usar farinhas de aveia em produtos cárneos têm sido justificadas pela sua habilidade de reter água nesses alimentos, inclusive durante o cozimento, por dar a sensação bucal similar à da gordura, pela ausência de sabor de cereais e porque contribui com fibra dietética nos produtos cárneos (BERRY, 1992).

A maltodextrina é polímero de D-glucose, produzida por hidrólise ácida ou enzimática de amido de milho. É utilizado para conferir viscosidade, aumentar o teor de sólidos solúveis, inibir a cristalização e controlar o ponto de congelamento. Quando utilizado como substitutos de gorduras, a relação água: maltodextrina é de 3: 1, produzindo um gel cujo valor calórico é de $1 \mathrm{kcal} / \mathrm{g}$ ou menos (SOBCZYNSKA; SETZER, 1991).

A pectina é um hidrocolóide composto de unidades de ácido anidrogalacturônico com graus variáveis de metoxilação. Pode ser extraída do albedo dos cítricos, de maçãs, sendo de ampla ocorrência entre os vegetais. Tem sido usada tradicionalmente como emulsificante, geleificante, estabilizante e espessante no preparo de uma grande variedade de produtos. Devido a sua versatilidade, a aplicação da pectina é muito ampla: molhos, patês, produtos cárneos, bolos, tortas, sobremesas geladas, glacês, coberturas, maionese e queijo (DUXBURY, 1991).

As pectinas altamente esterificadas necessitam, para sua geleificação de presença de açúcar e ácido. Com esta propriedade, utiliza-se pectina para a elaboração de geléias e doces em massa de frutas. A pectina purificada foi primeiramente extraída do bagaço de maçãs e, mais tarde, das frutas cítricas (extração mais comum atualmente). A sua qualidade está associada à capacidade de reter açúcar (HEBBEL, 1979).

A pectina é extraída da casca das frutas cítricas e da maçã por hidrólise ácida à quente seguida de precipitação alcoólica ou alcalina. Ela é submetida a seguir à purificação, secagem, moagem e homogenização. O controle das fases do processo de extração permite a obtenção da pectina sob duas formas:

- Pectinas de alto teor de metoxilas (ATM), com grau de esterificação maior que 50\%;

- Pectinas de baixo teor de metoxilas (BTM), com grau de esterificação menor que 50\%. A pectina ATM forma géis com conteúdo de sólidos solúveis acima de $55 \%$ e pH de 2,0 a 3,5. Este gel se estabiliza por interações hidrofóbicas do grupo éster metílico e por formação de pontes de hidrogênio intermoleculares. $\mathrm{O}$ pH ácido provoca a protonação dos 
grupos carboxílicos, diminui a repulsão eletrostática entre as cadeias e aumenta a formação de pontes de H. A adição de um sólido solúvel (como a sacarose) diminui a atividade de água, diminuindo a disponibilidade de água livre para solvatar o polissacarídeo, aumentando as interações hidrofóbicas entre os grupos éster metílicos (HEBBEL, 1979).

O gel ATM pode ser utilizado em geléias com pedaços ou polpa de frutas, iogurte líquido, sucos concentrados, bebidas lácteas acidificadas, sorvetes de frutas, entre outros.

A pectina BTM pode ser utilizada em geléias de baixo teor de sólidos $(15-60 \%)$, geléias dietéticas, iogurtes, doces de leite, entre outros. Para a formação de géis a pectina BTM necessita de sais de cálcio solúveis que podem estar presentes nas frutas, no leite ou podem ser adicionados como soluções diluídas de fosfato, cloreto (BARUFFALDI, 1998).

O gel de pectina BTM se estabiliza por interações entre os grupos carboxílicos e íons divalentes (cálcio). Esta pectina não necessita de açúcar para geleificar, porém a adição de 10 a 20\% melhora a textura do gel, tornando-o mais elástico e menos frágil.

A empresa Hercules Incorporated desenvolveu um produto denominado Slendid $®$, que contém essencialmente pectina de baixo teor de metoxil extraída de cítricos e padronizada pela adição de sacarose. É um pó, estável ao calor, PH, cisalhamanto, e alta concentração salina, a ser utilizado em concentração final de 0,5 a 3,0\%. Este produto é estável a altas temperaturas (exceto frituras), e na faixa de $\mathrm{pH}$ de 2 a 8 e resiste à agitação. A sua estabilidade térmica permite a utilização em alimentos que serão submetidos a processamento como esterelização, assamento e cocção por microondas. Em concentração da ordem de 1 a $2 \%$ pode substituir até $100 \%$ da gordura de um alimento, com excelente funcionalidade. $\mathrm{O}$ Slendid ${ }^{R}$ possui sabor neutro e confere a textura e a sensação bucal proporcionada pelas gorduras, através de sua textura cremosa. As partículas de gel imitam as propriedades de gorduras emulsificadas, mas não é recomendada em produtos no qual a gordura constitui a fase contínua como chocolate e bacon (CÂNDIDO, 1996).

A inulina é um carboidrato de reserva presente em diversos produtos vegetais, formado por uma cadeia de moléculas de frutose e uma molécula de glicose terminal. Dentre os vegetais que produzem a inulina, destacam-se o alho, cebola, aspargos as raízes de chicória (Cichoriumintybus L.), de alcachofra de Jerusalém (Helianthus tuberosus L.) e de yacon (Polymnia sonchifolia). Além das hortaliças, muitos cereais também contêm inulina, entre eles, o trigo, a cevada e o centeio.

O yacon é uma planta originária das regiões andinas que foi introduzida no Brasil no início dos anos 90. Trata-se de uma erva perene de talo piloso que possui, estocados em suas raízes tuberosas, os carboidratos frutose, glicose, sacarose e, principalmente, oligossacarídeos 
de baixo grau de polimerização, que podem chegar a $67 \%$ da matéria seca logo após a colheita. Os oligossacarídeos do yacon são do tipo $\beta(2 \rightarrow 1)$ frutooligossacarídeos com terminal sacarose, frutanas tipo inulina (MOSCATTO, 2004).

Esse carboidrato apresenta propriedades funcionais similares aos açúcares e xaropes de glucose, podendo substituir gorduras, açúcares ou amido em numerosas preparações alimentares. É moderadamente solúvel em água (10\% a temperatura ambiente), sendo muito solúvel a 50 a $60^{\circ} \mathrm{C}$. Contribui com sensação tátil bucal e corpo e melhora a estabilidade de espumas e emulsões. Seu valor calórico é cerca de $25 \%$ em relação ao dos açúcares, menor que $1,0 \mathrm{kcal} / \mathrm{g}$ (CÂNDIDO, 1996).

A inulina pode ser considerada como um ingrediente funcional, com baixa contribuição calórica, devido às suas propriedades nutricionais: não é quebrada no sistema digestivo humano, após a ingestão, devido à resistência à hidrólise oferecida pelas ligações $(2,1)$ entre as moléculas de frutose (ROBINSON, 1995).

No Brasil, ainda, não existem muitos estudos a respeito da exploração comercial da chicória para a extração de inulina, nem dos processos envolvidos. Em geral, esses estudos, ainda, são restritos à área agronômica, na seleção dos cultivares mais adequados ao nosso clima (OLIVEIRA et al., 2004).

De acordo com Laurenzo et al. (1999), os métodos, convencionalmente, utilizados para extrair inulina de produtos vegetais, tais como alcachofra de Jerusalém ou raízes de chicória, incluem as seguintes etapas: lavagem dos tubérculos; fatiamento ou moagem dos tubérculos; extração de inulina com água; tratamento do extrato com dióxido de carbono e cal; filtragem e recuperação da inulina por precipitação ou evaporação.

A inulina extraída de plantas, após a secagem, apresenta - se como um pó branco, amorfo, higroscópico, com odor e sabor neutros, com densidade de aproximadamente 1,35 e peso molecular de 1600 (HAULY, 2002).

Os frutooligossacarídeos (FOS) e a inulina têm sido designados como prebióticos e fibras alimentares solúveis, por sua não-digestibilidade pelas enzimas do trato digestivo humano, estímulo seletivo do crescimento e atividade de bactérias intestinais promotoras de saúde, especialmente as bifidobactérias, baixo valor calórico e a influência sobre a função intestinal e sobre os parâmetros lipídicos.

A aplicação da inulina na indústria alimentícia, a princípio, resumia-se à produção de bebidas similares ao café, devido ao seu sabor amargo. Entretanto, recentemente, descobriu-se que a inulina pode atuar como substituto do açúcar ou da gordura, com a vantagem de não resultar em incremento calórico. Além de atuar como substituto do açúcar ou da gordura, a 
inulina apresenta, também, algumas propriedades funcionais. Ela atua no organismo de maneira similar às fibras dietéticas, contribuindo para melhorar as condições do sistema gastrintestinal (OLIVEIRA et al., 2004).

Inulina e oligofrutoses vêm sendo incorporadas a diversos produtos alimentares, principalmente em produtos de padaria e confeitaria, como bolos, que gozam de grande aceitação pelo mercado consumidor devido às suas características reológicas: produtos leves e facilmente mastigáveis; apresentam textura porosa que facilita a digestão e são normalmente muito saborosos (MOSCATTO, 2004).

A maioria dos substitutos de gordura não contribui nas propriedades texturizantes de forma similar à gordura. A maior crítica a produtos low fat ou no fat se refere à sensação causada no consumo pelo decréscimo de textura, flavor e mouthfeel (sensação tátil bucal). Para substituir ou reduzir gordura com sucesso, o substituto deve não apenas resultar em produto com baixo valor calórico, mas, simultaneamente, suprir as propriedades funcionais, como estabilidade ao calor, emulsificação, espalhamento, textura e mouthfeel (SILVA, 1996).

A inulina é um modificador reológico e pode ser utilizado para aperfeiçoar a textura em sistemas de alimentos. Quando dissolvida em água, forma um creme semelhante ao produzido por uma gordura (gel). As propriedades de um gel podem ser aumentadas e otimizadas por meio de outros ingredientes como gomas e surfactantes (CÂNDIDO, 1996).

São propriedades da inulina, na panificação e produtos de cereais, sorvetes e produtos lácteos, o controle de umidade, baseado na capacidade de ligação de água da inulina, aumentando a vida de prateleira do produto, e o controle da viscosidade em bolos e pudins, particularmente, em massas com baixos teores de gordura.

Moscatto et al. (2004) utilizaram inulina e ou farinha de yacon como ingredientes na formulação de bolo de chocolate para avaliar a influência destes ingredientes sobre as propriedades químicas, físicas, a preferência e a estabilidade de armazenamento das formulações.

Foram preparados três tipos de bolos: formulação padrão $(P)$, formulação contendo a farinha de trigo substituída em $20 \%$ por farinha de yacon (A) e a formulação (B) contendo a farinha de trigo substituída em $40 \%$ por farinha de yacon e em $6 \%$ por inulina.

Os pesquisadores avaliaram neste estudo que os bolos das formulações A e B apresentaram propriedades químicas, físicas, preferência e estabilidade comparáveis ao da formulação padrão. Como vantagens, apresentaram menores valores de dureza e maiores teores em fibra alimentar total $(12,35 \%$ e $23,6 \%)$ em relação ao P $(9,02 \%)$. 
O valor calórico foi semelhante $(2,09 \mathrm{kcal}$ para A) e menor $(1,62 \mathrm{kcal}$ para $\mathrm{B}$ comparado a formulação padrão- 2,13 kcal) Portanto, a farinha de yacon e inulina podem ser utilizadas como ingredientes para bolo de chocolate, fornecendo produtos com características que atendem às exigências do mercado consumidor.

Em relação ao armazenamento, os bolos não apresentaram crescimento para bolores e leveduras, Salmonella $s p$ e coliformes totais, em nenhum dos dias avaliados. Em geral, considerando as condições e o tempo médio de exposição para venda de bolos comercializados prontos, os bolos das formulações P, A e B mostraram-se estáveis com relação ao teor de umidade, crescimento microbiano e valores de $\mathrm{pH}$, com destaque para o bolo da formulação B.

Os resultados da análise sensorial demonstraram que não houve diferença significativa entre os bolos das formulações $\mathrm{P}, \mathrm{A}$ e $\mathrm{B}$ quanto à preferência nos atributos cor, maciez e global. Com relação ao atributo aparência, referente à presença de porosidades ao longo do produto, o bolo da formulação A apresentou preferência semelhante ao bolo padrão, enquanto que o da formulação $\mathrm{B}$, apesar de ter sido tão preferido quanto ao da $\mathrm{A}$, foi menos apreciado que o bolo padrão para este atributo. Quanto ao sabor de chocolate, o bolo da formulação B foi mais apreciado que o da formulação A e ambos não diferiram significativamente do padrão $(5 \%)$.

Os pesquisadores concluíram que a farinha de yacon e inulina apresentou-se como ingredientes adequados para formulação de bolo de chocolate, uma vez que as formulações contendo inulina e/ou farinha de yacon demonstraram, de maneira geral, propriedades químicas, físicas, preferência e estabilidade de armazenamento comparáveis com as da formulação padrão para bolo de chocolate.

Possuem como vantagens a maciez e teor de fibra alimentar; valor calórico igual ou menor que o do bolo padrão e a presença de frutanas, como inulina e frutooligossacarídeos, que além de se apresentarem como fibras solúveis, possuem ação prebiótica às quais vários benefícios à saúde são atribuídos.

As gomas podem ser utilizadas para designar um material polímero a ser dissolvido ou dispersado em água, formando soluções ou dispersões viscosas. São designados também como hidrocolóides. Sua utilização deve-se ás inúmeras propriedades: estabilização de emulsões, suspensão de partículas, controle de cristalização. As gomas aprisionam grande quantidade de água, não proporcionam calorias e são muito importantes por acrescentarem características de textura e sensação tátil bucal aos substitutos de gorduras (CARR, 1993). 
As gomas podem ser classificadas em dois grupos: espessantes (amido, guar, xantana, arábica) ou geleificantes (amido, pectina, carragena, ágar). Podem ser obtidas de várias fontes: extrato de algas marinhas (ágar, carragena), extrato de sementes (guar), exudatos vegetais (arábica), microrganismos (fermentação - xantana, gelana) e celuloses quimicamente modificadas e pectinas (DZIEZAK, 1991).

A goma guar é retirada do endosperma do feijão do tipo guar (Cyamopsis). Sua importante propriedade é a capacidade de se hidratar rapidamente em água fria e atingir alta viscosidade. É usada como espessante de sopas, alimentos pobres em calorias e para aumentar o poder geleificante de outros espessantes (HEBBEL, 1979).

Além dessas vantagens, a goma guar é de baixo custo, além de ser um bom espessante e estabilizante. Sua formação é constituída por moléculas de manose e galactose na proporção de 2:1. Dissolve-se em água fria e geleifica quando em contato com borato (BARUFFALDI, 1998).

A goma xantana é um heteropolissacarídeo produzido pela Xanthomonas campestris. As soluções de goma xantana quando em baixas concentrações são pseudoplásticas, apresentam altos índices de viscosidade e tornam-se ralas quando sobre ela é aplicada força de cisalhamento. As operações de bombeamento na fase de produção do alimento são facilitadas pela pseudoplasticidade fazendo, com que produtos como, por exemplo, coberturas para saladas, fluam com facilidade de um frasco ou garrafa.

A goma xantana também apresenta excelente estabilidade em valores de $\mathrm{pH}$ extremos, na faixa de 2 a 11 , e altas temperaturas de 100 a $120^{\circ} \mathrm{C}$, além de poder ser dissolvida a quente ou a frio. É facilmente solúvel em água, produzindo alta viscosidade. Não é solúvel na maioria dos solventes orgânicos.

Em associação com outras gomas, proporciona textura lisa e cremosa, alimentos líquidos com qualidade superior as demais gomas. É utilizada para a fabricação de molhos para saladas, bebidas, geléias, produtos cárneos, enlatados, e sopas (BARUFFALDI, 1998).

A goma carragena é um hidrocolóide extraído de algas vermelhas. Ela forma géis termorreversíveis em presença de potássio e cálcio, adotando uma estrutura helicoidal. A carragena atua como geleificante, estabilizante, mantém partículas em suspensão, controla fluidez e confere a sensação tátil bucal de gordura (SHAND et al., 1994). 
O uso da carragena é indicado nos mais diversos produtos com baixo teor calórico (análogos de queijos, produtos cárneos, geléia de baixo teor de sólidos, chocolates, pudins, bebidas dietéticas) e em número ilimitado de alimentos convencionais (MARINE, 1991).

A goma-arábica é obtida da acácia, encontrada no Oriente Médio. É a goma vegetal mais utilizada, pois, além de espessante, é também um ótimo estabilizante de emulsões, por exemplo, da espuma de cerveja (BARUFFALDI, 1998).

Contribui na prevenção da cristalização do açúcar em caramelos, bem como na dissolução de essências cítricas nos refrigerantes (HEBBEL, 1979). Ainda constitui um agente encapsulante muito bom para óleos flavorizantes empregados em misturas em pó para bebidas, além de aprimorar a textura de sorvetes. Constantemente é usada juntamente com outros tipos de polissacarídeos, devido ao fato de apresentar baixas viscosidades quando em pequenas concentrações.

A goma arábica por sua fácil e rápida solubilidade em água facilita a reconstrução de produtos desidratados e de concentrados, de aromas. Ela não pode ser empregada em produtos que requerem alta viscosidade. É indicada para produtos aerados com baixo teor de gordura como manteiga, margarina, confeitos, coberturas e sobremesas geladas (DZIEZAK, 1991).

Pode ser encontrada sob várias formas: em pedaços, cristais e em pó. A forma mais elaborada é a goma atomizada, comercializada sob o nome de Fibregnum ${ }^{\circledR}$, obtida por processo físico de solubilização e purificação. Esse tratamento não acarreta nenhuma modificação química ou hidrólise ácida ou enzimática da molécula (MASGNAUX, 1994).

A goma gelana é obtida por fermentação aeróbica de Pseudomas elodea. A geleificação se produz por dispersão em água quente, em presença de íons monovalentes ou divalentes. $\mathrm{O}$ gel formado é resistente a ácidos, calor e enzimas. É destacada, pois quanto menor a concentração utilizada mais destaca o sabor em contato com a cavidade bucal (BARUFFALDI, 1998).

Zambrano et al. (2005) avaliaram o efeito das gomas guar, xantana e emulsificantes, em bolos, como substitutos de gordura. Nesse estudo foram consideradas as variáveis: umidade, lipídeos totais e valor calórico, para avaliação das formulações.

A goma xantana e a goma guar foram adicionadas a massas de bolos para melhorar a retenção da umidade, a estrutura do miolo, firmeza, elasticidade e maciez. Demonstrou-se que as propriedades das gomas são grandes ferramentas na substituição de gordura em produtos de 
panificação. No caso da goma guar, o único fator limitante para seu uso como substituto de gordura é o sabor residual que confere aos produtos (WARING, 1988).

Os autores verificaram que os emulsificantes promoveram grande aeração da massa do bolo, o que influencia de maneira direta no volume do bolo, em razão da formação e estabilização da espuma. Assim, a incorporação de ar na massa, durante o batimento, constitui um aspecto fundamental para a obtenção de bolos de boa qualidade, com bom volume e estrutura de miolo homogênea.

A celulose é um polímero totalmente insolúvel na água e não é digerido pelo organismo humano. É o principal componente das plantas e a fonte mais abundante de carboidratos complexos. Para que seu uso seja possível nos alimentos, é preciso que passe por uma transformação para um estado hidrossolúvel dispersável ou coloidal, para facilitar a aplicação da celulose no alimento (ANG; MILLER, 1991).

Pode ser extraída, purificada e comercializada como pó de celulose. Em produtos com baixo teor de gordura melhora a textura e o volume (a adição de 2 a $4 \%$ de celulose em bolos promove aumento do volume e da força da massa). Podem ser aplicadas a pães, bolos, molhos, queijos, alimentos congelados, bebidas, massas e produtos cárneos (ANG; MILLER, 1991).

A celulose microcristalina é obtida pela mistura tratamento da celulose com ácido, visando a sua hidrólise. Após esta reação, é tratada com carboximetilcelulose sódica (CMC), que atua como auxiliar de dispersão e colóide protetor. Posteriormente, a substância é submetida à secagem para formação de um agregado cristalizado a ser triturado. Os pós obtidos são insolúveis em água embora dispersíveis, de tal forma a constituir soluções coloidais e géis opacos (BARUFFALDI, 1998).

Essas dispersões quando originadas de celulose microcristalina podem ser floculadas quando em contato com eletrólitos. Com o aumento da proporção do colóide protetor aumenta relativamente à resistência à floculação.

A celulose cristalina, segundo Hebbel (1979), não é considerada um estabilizante completo. Por isso, é usada somente em conjunto com outras gomas, como a carragena.

Benassi et al. (2001) apresentaram um trabalho de revisão referente aos tipos de ingredientes desenvolvidos e/ou recomendados para uso em formulações de produtos de panificação com conteúdo calórico reduzido. 
Os pesquisadores detectaram que é mais fácil obter a redução calórica em bolos do que em pães, pois nos bolos a quantidade de gordura e açúcar é maior. Porém, a diminuição ou retirada de componentes pode afetar a estabilidade microbiológica do produto devendo ser usados ingredientes capazes de imobilizar a água (hidrocolóides, agentes de corpo).

No caso dos pães, o problema não se restringe às quantidades de açúcar e gordura, sendo necessário diminuir também a quantidade de farinha de trigo, que é o ingrediente majoritário e excelente fonte de amido e proteína. Ambos os componentes apresentam o mesmo valor calórico, porém a proteína (glúten) desempenha função estrutural indispensável neste produto, não podendo sofrer redução acentuada. $\mathrm{O}$ amido é mais facilmente substituível por ingredientes menos calóricos, como fibras, amidos modificados, maltodextrinas, polidextrose, hemiceluloses e gomas.

\subsubsection{Substitutos de gorduras a base de produtos similares a gorduras}

São substâncias similares à gordura (Tabela 3), mas resistentes à hidrólise pelas enzimas digestivas. Os substitutos de gordura a base de gorduras sintéticas estão em processo de desenvolvimento para a utilização em alimentos. Além da versatilidade, apresentam alta estabilidade térmica, podendo ser utilizados em frituras. São predominantemente emulsificantes (CÂNDIDO, 1996).

As gorduras naturais consistem de glicerol esterificado, com um a três ácidos graxos. A estrutura básica pode ser redesenhada das seguintes maneiras:

- A parte glicerol pode ser substituída por um álcool alternativo;

- Os ácidos graxos podem ser substituídos por outros ácidos, como: ácidos carboxílicos ramificados;

- A ligação éster pode ser reduzida a uma ligação éter.

Uma outra maneira de desenvolver substitutos de gorduras seria a tentativa de reproduzir as propriedades de óleos e gorduras comestíveis, utilizando-se polímeros ou óleos naturais, cujas propriedades químicas não estejam relacionadas com a estrutura triglicerídica (LIMA; NASSU, 1996).

Podem ser utilizados materiais poliméricos não absorvíveis já existentes, ou desenvolvidos de tal modo que apresentem características similares às gorduras convencionais, e desenvolver microcápsulas que iriam substituir o glóbulo de gordura em 
alimentos emulsificados. Finalmente, certos produtos naturais, como o óleo de jojoba poderiam ser utilizados como substitutos de gordura em potencial (LIMA; NASSU, 1996).

Tabela 3: Tipos de substitutos de gorduras a base de lipídeos

\begin{tabular}{|c|c|c|}
\hline Tipos de lipídeos & Fonte & Aplicação \\
\hline Caprenina & $\begin{array}{l}\text { Triacilglicerol contendo: } \\
\text { - Ácido caprílico } \\
\text { - Ácido Behênico }\end{array}$ & $\begin{array}{l}\text { - Doces macios } \\
\text { - Coberturas } \\
\text { - Manteiga de cacau }\end{array}$ \\
\hline $\begin{array}{l}\text { Ésteres de ácidos graxos com } \\
\text { sacarose (Olestra } \AA)\end{array}$ & Poliéster de sacarose & $\begin{array}{l}\text { - Bebidas } \\
\text { - Margarinas } \\
\text { Alimentos de baixa caloria }\end{array}$ \\
\hline $\begin{array}{l}\text { Mono e diésteres de } \\
\text { propilenoglicol }\end{array}$ & $\begin{array}{l}\text { Diésteres de 1,2- } \\
\text { propileno glicol }\end{array}$ & $\begin{array}{l}\text { - Produtos á base de } \\
\text { chocolate }\end{array}$ \\
\hline $\begin{array}{l}\text { Ésteres de ácidos } \\
\text { policarboxílicos }\end{array}$ & $\begin{array}{l}\text { Ácido policarboxílico, } \\
\text { amino, citrato. }\end{array}$ & $\begin{array}{l}\text { - Maionese } \\
\text { - Margarina }\end{array}$ \\
\hline $\begin{array}{l}\text { Malonato de dialquil } \\
\text { dihexadecil }\end{array}$ & $\begin{array}{l}\text { Éster de álcool graxo de } \\
\text { ácido malônico e alquil } \\
\text { malônico. }\end{array}$ & $\begin{array}{l}\text { - Margarina } \\
\text {-Maionese } \\
\text { - Frituras e assamento }\end{array}$ \\
\hline $\begin{array}{l}\text { Glicerol propoxilado } \\
\text { esterificado }\end{array}$ & Glicerol & $\begin{array}{l}\text { - Substitui total ou } \\
\text { parcialmente óleos e } \\
\text { gorduras na elaboração de } \\
\text { alimentos através de frituras. }\end{array}$ \\
\hline Ésteres de poliglicerol & $\begin{array}{l}\text { Gorduras híbridas, ácidos } \\
\text { graxos e poliglicerol. }\end{array}$ & $\begin{array}{l}\text { - Chocolates } \\
\text { - Maionese } \\
\text { - Óleo vegetal }\end{array}$ \\
\hline Éteres & Síntese de 1,3 diéter & - Óleos vegetais \\
\hline Polímeros de silicone & Poliorganosiloxanos & $\begin{array}{l}\text { - Óleos vegetais } \\
\text { - Maionese, patês } \\
\text { - Bolos, produtos lácteos. } \\
\text { - Cereais, creme de } \\
\text { amendoim. }\end{array}$ \\
\hline Óleo de jojoba & $\begin{array}{l}\text { Semente de arbustos de } \\
\text { Simnonddsia californica }\end{array}$ & $\begin{array}{l}\text { - Óleos vegetais } \\
\text { - Cobertura de chocolates }\end{array}$ \\
\hline
\end{tabular}


Tabela 3: Tipos de substitutos de gorduras a base de lipídeos (continuação)

\begin{tabular}{|l|l|l|}
\hline \multicolumn{1}{|c|}{ Tipos de lipídeos } & \multicolumn{1}{c|}{ Fonte } & \multicolumn{1}{c|}{ Aplicação } \\
\hline \multirow{2}{*}{ TCM } & $\begin{array}{l}\text { Interesterificação com } \\
\text { óleo de soja, girassol e } \\
\text { arenque, após prévia } \\
\text { hidrólise }\end{array}$ & $\begin{array}{l}\text { - Bolos } \\
\text { - Condimentos } \\
- \text { Alimentos assados } \\
\text { Frituras e queijos }\end{array}$ \\
\hline Salatrim $\Theta$ & $\begin{array}{l}\text { Interesterificação de } \\
\text { óleos vegetais como soja } \\
\text { ou canola }\end{array}$ & - Óleos vegetais \\
\hline Sorbestrin $\Theta$ & - & - Óleos vegetais \\
\hline
\end{tabular}

Fonte: CÂNDIDO, 1996

O éster de ácidos graxos com sacarose (Olestra $\Theta)$ é um poliéster de sacarose com mistura de hexa, hepta e octa éster de sacarose com ácidos graxos de cadeia longa. Estável em altas temperaturas (frituras), assegura textura, sabor e sensação bucal proporcionada pelas gorduras convencionais. A ingestão de Olestra pode ter efeito benéfico na redução de TAG e LDL - colesterol plasmático, sem alterar os níveis de HDL- colesterol. O efeito é mais marcante em indivíduos hiperlipidêmicos, o que pode sugerir seu uso como produto dietético para populações clínicas específicas (CÂNDIDO, 1996).

Esses ésteres de carboidrato com ácidos graxos são facilmente sintetizados por transesterificação ou esterificação com cloretos ou anidridos de ácidos, ou ácidos graxos de cadeia linear. Em função das combinações utilizadas podem ser obtidos produtos com as propriedades físico-químicas desejadas. O Olestra $®$ é produzido a partir de óleos vegetais e sacarose (BEST, 1992).

Devido à disponibilidade de gordura do leite nos Estados Unidos, Drake et al. (2004) desenvolveram poliésteres de sacarose utilizando ácidos graxos derivados de gordura do leite, gordura de coco e de carne. Após analisar o perfil de ácidos graxos e as suas propriedades, por meio de calorimetria diferencial e penetromia, constataram que é necessária a suplementação com ácidos graxos de outra fontes, para o ajuste das características de fusão, dureza da gordura e propriedades viscoelásticas da utilização de ácidos graxos provenientes da gordura do leite.

Além da estabilidade em altas temperaturas (frituras), esse substituto assegura a textura,o sabor e a sensação bucal proporcionadas pelas gorduras convencionais. Apresenta 
propriedades físicas semelhantes aos triacilglicerois. Drake et al (1994) avaliaram

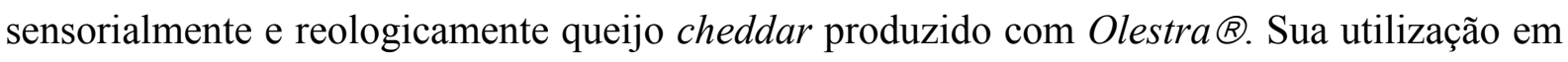
queijos não afeta a umidade, lipídeos totais, produção de ácidos, e a firmeza do queijo.

Henry et al. (1992) analisaram comparativamente os produtos de frituras de

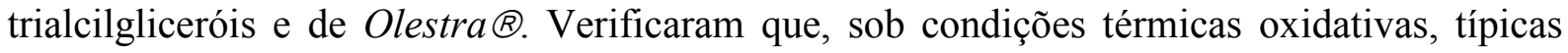
das encontradas na fritura de alimentos, o Olestra $®$ sofre o mesmo tipo de reações que os óleos vegetais, incluindo formação de polímeros, porque os ácidos graxos são semelhantes. Os autores isolaram e identificaram os compostos formados, concluindo que as reações que ocorrem são independentes do esqueleto (sacarose e glicerol) ao qual os ácidos graxos estão ligados.

Allgood et al. (2000) relataram em sua revisão bibliográfica os efeitos observados na introdução no mercado de snacks contendo olestra. O estudo ofereceu uma oportunidade de avaliar a aplicação do olestra em alimentos no consumo de uma população normal e compararam os resultados com os dados de segurança de uso previamente estabelecidos em testes clínicos nos quais indivíduos ingeriram quantidades predeterminadas de alimento com olestra, em intervalos prescritos.

Além disso, um inquérito pós-mercado foi elaborado para avaliar a experiência do consumidor e a segurança do olestra neste contexto de consumo real. Os comentários dos clientes foram registrados por meio do histórico de telefonemas gratuitos às empresas. Os dados coletados foram avaliados por médicos especialistas. Cerca de $10 \%$ dos telefonemas reportavam efeitos relacionados à saúde, a maioria dos quais de natureza gatrointestinal. Estudos clínicos já haviam sido conduzidos para determinar o potencial dos efeitos gastrointestinais das quantidades equivalentes ao consumo de olestra reportado nos telefonemas gratuitos.

Os autores concluíram que os efeitos clínicos levantados foram iguais àqueles encontrados comumente na população em geral e a análise dos dados não evidenciaram nenhuma razão biológica que leve à conclusão quanto a efeitos sérios significativos, deletérios à saúde, causados pelo consumo de olestra.

O óleo de jojoba é um líquido fluído a temperatura acima de $100^{\circ} \mathrm{C}$, sendo uma mistura de ésteres lineares de ácidos graxos insaturados de cadeia longa e álcoois graxos, isto é, os componentes álcool e ácido deste óleo contêm principalmente 20 a 22 carbonos, cada um contendo uma insaturação. Devido a esta estrutura, parece ter potencial para ser utilizado como substituto de gorduras (CÂNDIDO, 1996). 
Várias pesquisas têm sido desenvolvidas para verificar a digestibilidade do óleo de jojoba, que não é afetada por lipases que hidrolisam óleos e gorduras vegetais e animais, sendo, portanto, não metabolizados. Pode ser utilizado em molhos para salada e óleos de mesa. O sabor e estabilidade deste óleo são comparáveis aos óleos de soja, açafrão e gergelim. Possibilidades de este óleo ser um agente redutor de colesterol têm sido estudadas (LIMA; NASSU, 1996).

Margarinas formuladas com óleo de jojoba são mais firmes, de estrutura mais arenosa e não fundem tão rapidamente como as convencionais. Sua alta temperatura de solidificação limita seu uso em molho para salada. A utilização comercial é limitada devido ao alto custo, baixa disponibilidade e questões relacionadas à segurança do produto. $\mathrm{O}$ material hidrogenado é especialmente indicado para coberturas de chocolate (IYENGAR, 1991).

A Caprenina é um triacilglicerol (TAG) contendo ácido caprílico $\left(\mathrm{C}_{8}\right)$, ácido cáprico $\left(\mathrm{C}_{10}\right)$ e ácido behênico $\left(\mathrm{C}_{22}\right)$. Seu valor calórico é em torno de 4 a $5 \mathrm{kcal} / \mathrm{g}$.

Vários estudos importantes indicaram que a caprenina é metabolizada como os lipídeos contendo ácidos graxos de cadeia média e de cadeia longa. Baseado em seus estudos, a Procter \& Gamble (CÂNDIDO, 1996), detentora da patente do produto, solicitou sua liberação à FDA para uso, atualmente limitado ao preparo de confeitos, em doces macios e coberturas.

A semelhança nas propriedades da caprenina, conferidas pelos ácidos cáprico e caprílico, com a manteiga de cacau, justifica sua aplicação. O produto vem sendo produzido em escala industrial na Dinamarca. Foi comercialmente introduzido no mercado em combinação com polidextrose (BEST, 1992).

Os Triglicerídeos de Cadeia Média (TCM) têm sido recomendados como substitutos de gorduras e são usados desde os anos de 1950 para pessoas com disfunções na absorção de lipídios. São recomendados para pessoas que não podem consumir TAG que contenham ácidos graxos de cadeia longa. O óleo de coco é uma boa fonte, tem grande teor de TAG com 6 a 10 carbonos (cadeia saturada), sendo considerado fonte de TCM, portanto, tem baixa tendência de acumular-se no tecido adiposo (LIMA; NASSU, 1996).

Óleos e gorduras ricos em TCM podem ser utilizados a temperaturas relativamente altas (frituras). Seu valor calórico é pouco inferior ao de um TAG normal. São insípidos, inodoros, incolores e resistentes à oxidação (não possuem ligações duplas), além de serem 
bom meio de solubilização de compostos lipossolúveis: corantes, sabores, vitaminas e fármacos (LIMA; NASSU, 1996).

Os ésteres de poliglicerol são gorduras híbridas com cadeias laterais de ácidos graxos e um esqueleto central de poliglicerol (EYDT, 1994). As poliglicerinas são produzidas em meio alcalino e a $230^{\circ} \mathrm{C}$. A síntese é relativamente simples, a afinidade pela água aumenta com o aumento da proporção de poliglicerina e diminui com o aumento do peso molecular dos ácidos graxos (LABARGE, 1998).

Apresentam-se com sabor e aparência de gorduras e um efeito positivo na palatabilidade, mas são de menor valor energético, produzindo de 6,0 a $6,5 \mathrm{kcal} / \mathrm{g}$. O uso de pequenas quantidades destes ésteres parciais em emulsões aquosas proporciona a sensação bucal dos alimentos cremosos. Em concentrações mais elevadas seu uso é limitado pelo odor, gosto amargo e coloração escura, requerendo purificação adicional (RICE, 1993).

Os ésteres de poliglicerol são empregados devido às suas propriedades, emulsificantes, controlando a cristalização, aeração e estabilidade de espumas e emulsões (TUCOULAT, 1994).

Os polímeros de silicone são compostos por $15 \%$ de peso de carbono orgânico e apresentam peso molecular aproximado de $500 \mathrm{~g} / \mathrm{mol}$. São inertes, não absorvíveis, resistentes à hidrólise, oxidação e degradação. A aplicação destes polímeros inclui: óleo de frituras, maionese, bolos, cereais, creme de amendoim, produtos lácteos e patês (SINGHAL, 1991).

O Salatrim \& é uma mistura de ácidos graxos de cadeia longa e cadeia curta, esterificados ao glicerol. Ele faz parte da família de triacilgliceróis estruturados, produzidos por interesterificação de óleos vegetais como soja ou canola, altamente hidrogenados, com triacilgliceróis de ácido acético e/ou propiônico e /ou burítico.

O Salatrim $\Theta$ proporciona as mesmas propriedades físicas da gordura, com aproximadamente 4,5 a 6,0 kcal/g (NABISCO, 1994).

Hayes et al. (1994) revisaram os mecanismos de digestão, absorção e metabolismo de triacilgliceróis estruturados, concluindo pela segurança do Salatrim $®$. Não foram verificados efeitos tóxicos em ensaios biológicos para toxicidade subcrônica no nível de 2\%, $5 \%$ e 10\% de salatrim, comparativamente a dieta com óleo de milho, com duração de 13 semanas. Em estudos clínicos, Salatrim ${ }^{\circledR}$ foi bem tolerado em doses diárias de até $60 \mathrm{~g}$.

A empresa Pfizer - Food Science Group, está desenvolvendo um substituto para óleos vegetais, denominado Sorbetrin, é um ester hexa do ácido fatty do sorbitol, o qual pode ser 
utilizado em aplicações que utilizem temperaturas elevadas, incluindo frituras. Contém 1,5 $\mathrm{kcal} / \mathrm{g}$ (CÂNDIDO, 1996).

A grande maioria dos produtos citados, exceto os análogos de lipídeos (gorduras sintéticas) que ainda estão em desenvolvimento, são ingredientes cuja segurança está estabelecida, por avaliações toxicológicas realizadas por instituições internacionais. São consagrados para o uso, tendo sido aceitos como substância GRAS pela FDA nos Estados Unidos (CÂNDIDO, 1996).

\subsubsection{Legislação}

O FDA não reconhece os substitutos de gordura como uma classe distinta, para propósito de avaliação. Apesar de os substitutos de gorduras não serem alimentos, não são diferentes de qualquer outro componente alimentício que se enquadre na seção de Atos de Alimentos, Drogas e Comésticos. Porém, os substitutos de gordura são diferentes de outros aditivos utilizados em alimentos, pois podem representar um terço das calorias consumidas e os testes com estes produtos criam problemas científicos que não são normalmente encontrados em testes com aditivos mais tradicionais, consumidos em quantidades muito menores (LIMA; NASSU, 1996).

A princípio, todos os substitutos de gordura devem ter a afirmação Generally Recognized As Safe - GRAS, da Food and Drug Administration - FDA (Tabelas 1 a 3). Muitos destes produtos são resultados de técnicas comerciais de aquecimento, acidificação e mistura de ingredientes comuns encontrados em alimentos, como carboidratos, proteínas de ovo e leite e/ou água, para imitar as propriedades organolépticas da gordura. Outros processos envolvem reações enzimáticas (LIMA; NASSU, 1996).

A Resolução n ${ }^{\circ}$ 04/88 - CNS /MS de 24/11/88 reviu as tabelas de aditivos do Decreto $n^{\circ} 55871$ de 26/3/65 e permitiu a utilização, entre os Estabilizantes (ET) e/ou Espessantes (EP), dos seguintes aditivos: amidos modificados, celulose microcristalina, carboximetilcelulose, goma arábica, guar e xantana. Além dessa resolução, outros atos administrativos liberaram ingredientes ou estabeleceram limites para sua utilização: goma guar, goma xantana, goma arábica, carboximetilcelulose (Portaria $\mathrm{n}^{\circ} 7-$ DINAL/ MS DE 06/06/89); goma carragena (Portaria $\mathrm{n}^{\circ} 38$ - DINAL /MS DE 15/12/89 E Portaria $n^{\circ} 57$ DIPROD / MS DE 17/4/91); Simplesse ${ }^{\circledR}$ (Ofício DOI/DIPOA/AUP $n^{\circ}$ 228/93) e polidextrose (Portaria $n^{\circ} 53=$ DIPROD/MS de 04/04/91). Éstéres de poliglicerol de ácidos graxos (Autorização DIPROD /MS N 188 /91 e 236/91) e ésteres de sacarose de ácidos 
graxos (Resolução $n^{\circ} 04 / 88$ - CNS/ MS) são permitidos como estabilizantes pela legislação brasileira (ABIA, 1993).

A Resolução - RDC n 27, de 13 de fevereiro de 2004 regulamenta a qualidade de Alimentos para Fins Especiais. Ela preconiza a necessidade de constante aperfeiçoamento das ações de controle sanitário na área de alimentos, visando à proteção da saúde da população, e a necessidade de fixar a identidade e as características mínimas de qualidade a que deve obedecer ao uso de aditivos; os parâmetros para aprovação de uso de aditivos mencionados no Decreto n 55.871 de 26 de março de 1965; a necessidade de adequar o uso de aditivos, regulamentado pela Resolução CNS/MS nº 04/88, em virtude da implementação de normas específicas sobre Informação Nutricional Complementar e Alimentos para Fins Especiais.

O uso de aditivos para alimentos com Informação Nutricional Complementar e Alimentos para Fins Especiais deve seguir os seguintes requisitos:

- Os alimentos cujo valor energético e ou teor de nutrientes tenha(m) sido alterado(s), com o objetivo de atender aos parâmetros constantes dos Regulamentos Técnicos de Informação Nutricional Complementar e de Alimentos para Fins Especiais, podem utilizar os aditivos alimentares com as mesmas funções tecnológicas e nos mesmos limites máximos previstos para o alimento convencional correspondente.

- O uso de aditivo não previsto no alimento convencional similar, ou em limite maior que aquele já autorizado, é permitido quando justificada a necessidade tecnológica decorrente da substituição total ou parcial de ingredientes.

- Os alimentos e bebidas cujo conteúdo de açúcares foi alterado, associado ou não à alteração de outros nutrientes e ou valor energético, com o objetivo de atender ao Regulamento Técnico de Informação Nutricional Complementar, podem utilizar os edulcorantes naturais e artificiais previstos na legislação em vigor.

- Os limites máximos de uso dos edulcorantes naturais e artificiais nos alimentos e bebidas especificados no item anterior, com exceção dos alimentos de reduzido teor de açúcares, são os mesmos permitidos para alimentos e bebidas dietéticos. Para os alimentos de reduzido teor de açúcares, os limites máximos não devem ser superiores a $75 \%$ dos limites máximos previstos para os alimentos e bebidas dietéticos.

- As classes dos alimentos e bebidas listados a seguir, formulados com o objetivo de atender ao Regulamento Técnico de Alimentos para Fins Especiais, podem utilizar os edulcorantes naturais e artificiais previstos na legislação em vigor, nos seus respectivos limites máximos: 
- Alimentos para Dietas com Restrição de Açúcares, exceto os Adoçantes Dietéticos, que devem obedecer à legislação específica;

- Alimentos para Controle de Peso e

- Alimentos para Dieta com Ingestão Controlada de Açúcares.

Em outubro 1997, a Secretaria de Vigilância Sanitária do Ministério da Saúde, publicou a definição de aditivos alimentares. Segundo a Portaria $n^{0}$ 540/ 97, o aditivo alimentar é qualquer ingrediente adicionado intencionalmente aos alimentos, sem propósito de nutrir, com o objetivo de modificar as características físicas, químicas, biológicas ou sensoriais, durante a fabricação, processamento, preparação, tratamento, embalagem, acondicionamento, armazenagem, transporte ou manipulação de um alimento. Ao agregar-se poderá resultar em que o próprio aditivo ou seus derivados se convertam em um componente de tal alimento. Esta definição não inclui os contaminantes ou substâncias nutritivas que sejam incorporadas ao alimento para manter ou melhorar suas propriedades nutricionais.

A segurança dos aditivos é primordial. Isto supõe que antes de ser autorizado o uso de um aditivo em alimentos este deve ser submetido a uma adequada avaliação toxicológica, em que se deve levar em conta, entre outros aspectos, qualquer efeito acumulativo, sinérgico e de proteção, decorrente do seu uso.

De acordo com a determinação, as funções dos aditivos alimentares, especificados pela Portaria 540/97 são: agente de massa (substância que proporciona o aumento de volume e/ou da massa dos alimentos, sem contribuir significamente para o valor energético do alimento); antiespumante (substância que previne ou reduz a formação de espuma); antiumectante (substância capaz de reduzir as características higroscópicas dos alimentos e diminuir a tendência de adesão, umas às outras, das partículas individuais); antioxidante (substância que retarda o aparecimento de alteração oxidativa no alimento); corante (substância que confere, intensifica ou restaura a cor de um alimento); conservador (substância que impede ou retarda a alteração dos alimentos provocada por microrganismos ou enzimas); edulcorante (substância diferente dos açúcares que confere sabor doce ao alimento); espessantes (substância que aumenta a viscosidade de um alimento); geleificante (substância que confere textura através da formação de um gel); estabilizante (substância que torna possível a manutenção de uma dispersão uniforme de duas ou mais substâncias imiscíveis em um alimento); aromatizante (substância ou mistura de substâncias com propriedades aromáticas e/ou sápidas, capazes de conferir ou reforçar o aroma e/ou sabor dos alimentos); umectante (substância que protege os alimentos da perda de umidade em ambiente 
de baixa umidade relativa ou que facilita a dissolução de uma substância seca em meio aquoso); regulador de acidez (substância que altera ou controla a acidez ou alcalinidade dos alimentos); acidulante (substância que aumenta a acidez ou confere um sabor ácido aos alimentos); emulsificante (substância que torna possível a formação ou manutenção de uma mistura uniforme de duas ou mais fases imiscíveis no alimento) e realçador de sabor (substância que ressalta ou realça o sabor/aroma de um alimento).

O Ministério da Agricultura, Pecuária e Abastecimento - Instrução Normativa n . 29, de 27 de setembro de 1999 - regulamenta a Bebida Dietética e de Baixa Caloria. Essa norma regula que as bebidas dietéticas devem possuir teor de açúcar menor que $0,5 \mathrm{~g} / 100 \mathrm{ml}$. Este limite pode ser maior nos refrigerantes dietéticos quando proveniente da adição de suco de fruta, permitido o uso do termo "Diet".

As calorias devem ser classificadas como: baixas ou light (máximo de $40 \mathrm{kcal} / 100 \mathrm{~g}$ ou $20 \mathrm{kcal} / 100 \mathrm{ml}$ ); reduzidas (no mínimo $25 \%$ de calorias a menos do que o alimento de referência e diferença maior que $40 \mathrm{kcal} / 100 \mathrm{~g}$ ou $20 \mathrm{kcal} / 100 \mathrm{ml})$.

As condições para declarar o conteúdo de gorduras e valor energético são: gorduras totais - baixas ou light (máximo de $3 \mathrm{~g}$ de gordura em $100 \mathrm{~g}$ ou 1,5 g de gordura em 100ml); reduzidas (no mínimo 25\% a menos de gordura do que o alimento de referência). A diferença deve ser maior que $3 \mathrm{~g}$ de gordura em $100 \mathrm{~g}$ ou $1,5 \mathrm{~g}$ em $100 \mathrm{ml}$.

As gorduras totais (baixas ou light - máximo de $1,5 \mathrm{~g}$ de gordura saturada em $100 \mathrm{~g}$ ou $0,75 \mathrm{~g} \mathrm{em} 100 \mathrm{ml})$. A energia fornecida por gordura deve ser no máximo $10 \%$ do valor energético; reduzidas - no mínimo $25 \%$ a menos de colesterol que no alimento de referência. A diferença deve ser maior que $1,5 \mathrm{~g} / 100 \mathrm{~g}$ ou $0,75 \mathrm{~g} / 100 \mathrm{ml}$.

Para o colesterol, as indústrias deverão seguir as seguintes normas: baixo ou light (máximo de 20mg de colesterol em 100 g ou $10 \mathrm{mg}$ de colesterol em $100 \mathrm{ml}$ e máximo de 1,5 g de gordura saturada em $100 \mathrm{~g}$ ou $0,75 \mathrm{em} 100 \mathrm{ml}$ ). A energia fornecida por gordura saturada deve ser no máximo 10\% do Valor Energético; reduzido (no mínimo 25\% a menos de colesterol que o alimento de referência). A diferença deve ser maior que $20 \mathrm{mg}$ colesterol/100g ou $10 \mathrm{mg}$ de colesterol em 100ml (ANVISA, 2002).

Os alimentos para fins especiais são formulados ou processados adequadamente à utilização em dietas diferenciadas e ou opcionais, atendendo às necessidades de pessoas em condições metabólicas e fisiológicas específicas. Eles podem ser classificados em:

- Alimentos para dietas com restrição de nutrientes;

- Alimentos para ingestão controlada de nutrientes; 
- Alimentos para grupos populacionais específicos.

Os alimentos para os quais deve ser utilizada a palavra Diet podem ser:

- Alimentos para dietas com restrição de carboidratos - devem conter no máximo 0,5 g do dissacarídeo de referência /100g ou 100mlno produto final a ser consumido.

- Alimentos para dietas com restrição de gorduras - devem conter no máximo $0,5 \mathrm{~g}$ de gordura total $/ 100 \mathrm{~g}$ ou $100 \mathrm{mlno}$ produto final a ser consumido.

- Alimentos para dietas com restrição de proteínas - devem ser totalmente isentos do componente associado ao distúrbio para ao qual se destina (ANVISA, 2002). 


\section{CONCLUSÃO}

Estudos epidemiológicos, clínicos e ensaios biológicos têm demonstrado existir alta correlação entre a ingestão de alimentos ricos em gorduras saturadas, colesterol e risco de coronariopatias, diabetes, obesidade e em alguns casos, câncer. Demonstraram também que a consciência do fato faz com que as pessoas mudem suas práticas alimentares.

Devido ao surgimento dessas doenças crônico não transmissíveis por mau hábito alimentar (alimentos gordurosos e pobres em fibras), muitas empresas alimentícias têm desenvolvido produtos com substitutos de gorduras para reduzir o valor calórico e, conseqüentemente, o teor das gorduras maléficas nos alimentos. Muitos fatores foram avaliados na comercialização desses produtos, como: objetivos e necessidade de produção, efeito da modificação de composição sobre as características sensoriais, regulamentação e aspectos econômicos.

Uma das grandes preocupações das empresas foi produzir alimentos com as mesmas propriedades funcionais e organolépticas dos lipídios convencionais, com significativa redução de energia, incluindo estabilidade térmica, emulsificação e aeração, lubrificação, além de contribuírem com sabor, cor e textura.

Não existe um único substituto de gordura com todas essas características, mas já estão disponíveis vários ingredientes (substitutos a base de carboidrato, proteína e lipídeo) que apresentam algumas destas propriedades, e que na correta combinação e proporção, permitem o desenvolvimento de um número muito grande de produtos alimentícios.

Muitos substitutos de gordura já estão regulamentados, possuem o selo GRAS pela FDA nos Estados Unidos e podem ser fabricados com excelente qualidade com os aditivos e ingredientes permitidos pela legislação em vigor.

Neste estudo, podemos perceber, então, que os substitutos de gorduras são muito úteis para as pessoas que buscam uma alimentação mais saudável e para aquelas que necessitam de consumir esses produtos devido alguma patologia gerada pelo alto consumo de comidas gordurosas. Esse foi um dos grandes passos para a evolução da tecnologia dos alimentos. 


\section{REFERÊNCIAS BIBLIOGRÁFICAS}

ABIA. Associação Brasileira das Indústrias de Alimentação. Compêndio de Legislação de Alimentos. São Paulo: ABIA, 1989/1993.

AKOH, C. Optimized synthesis of sucrose polyesters: comparision of physical properties of sucrose polyesters, raffinose polyesters and salad oil. Journal of Food Science. Chicago, vol 55, 1990.

ALLGOOD et al. Postmarketing Surveillance of New Food Ingredients: Results from the Program with the Fat Replacer Olestra. Regulatory Toxicology and Pharmacology, 2000.

ANDERSON, E. T; BERRY, B. W. Sensory, shear, and cooking properties of lower-fat beef patties made with inner pea fiber. J. Food Sci., v. 65. n. 5, 2000.

ANDERSON, K. Ingredientes of reduced calorie foods. Food for the 90`s. London, 1990.

ANG, J.F; MILLER W.B. Multiple functions of powdered cellulose as a food ingredient. Cereal Foods World, vol 36, 1991.

ANVISA. Agência Nacional de Vigilância Sanitária. Aditivos Alimentares - definições, classificação e emprego. Resolução RDC Nº 540, de 27 de outubro de 1997.

ANVISA. Agência Nacional de Vigilância Sanitária. Alimentos para fins especiais. Resolução RDC N 27, de 13 de fevereiro de 2004.

AUVINEN, J. Globin - A new functional protein for the food industry. Int. Food Ingred., Leicestershire, vol.2, 1992.

BARUFFALDI, Renato; OLIVEIRA, M. N. Fundamentos de Tecnologia de Alimentos. São Paulo: Atheneu, 1998.

BENASSI T.V; WATANABE . E; LOBO R.A. Produtos de panificação com conteúdo calórico reduzido. B.CEPPA, Curitiba, vol. 19, $\mathrm{n}^{\circ} .2,2001$.

BERRY, B. W. Low fat level effects on sensory, shear, cooking, and chemical properties of ground beef patties. J. Food. Sci. vol. 57, $\mathrm{n}^{\circ}$. 3, 1992.

BERRY, B. W. Sodium alginate plus modified tapioca starch improves properties of lowfat beef patties. J. Food Sci., vol. 62, nº. 6, 1997.

BEST, D et al. Fat and cholesterol reduced foods. Prepared Foods. Washington, vol 161, 1992.

BEST. D. Prepared Foods. Chicago, vol 161, 1992.

BILIADERIS, C.G. The structure and interactions of starch with food constituintes. Canadian Journal Physiology Pharmacology, 1991.

BLEIL, Suzane. O Padrão Alimentar Ocidental: considerações sobre a mudança de hábitos no Brasil. Cadernos de Debate, Vol. VI. Unicamp, 1998. 
BOURSIER, B. Applications alimentaires des amidons modifies. Industries et Agricoles, Paris, vol 111, 1994.

BRASIL, Ministério da Agricultura. Anexo I. Instrução normativa $n^{\circ} 21$, de 31 de julho de 2000. Regulamento técnico de identidade e qualidade de patê. Diário Oficial, Brasília, 03 de agosto, 2000.

BRASIL. Conselho Nacional de Segurança Alimentar e Nutricional. II Conferência Nacional de Segurança Alimentar e Nutricional: Carta de Olinda. Olinda, 2004.

BRASIL. Ministério da Agricultura e do Abastecimento. Secretaria de Defesa Agropecuária. Departamento de Inspeção de Produtos de Origem Animal. Regulamentos Técnicos de Identidade e Qualidade de Leite e Produtos Lácteos. Portaria $\mathrm{n}^{\circ} 359$. Regulamento técnico para fixação de identidade e qualidade do requeijão cremoso. Brasília, 1997.

BRASIL. Ministério da Agricultura e do Abastecimento. Secretaria Nacional de Defesa Agropecuária. Departamento de Inspeção de Produtos de Origem Animal. Divisão de Normas Técnicas. Regulamento técnico de identidade e qualidade de leite e produtos lácteos. Brasília, 1997.

BRASIL. Ministério da Saúde. A Promoção da alimentação saudável como instrumento de prevenção e combate ao sobrepeso e obesidade. Secretaria de atenção á saúde. Departamento de atenção básica. Coordenação- geral da política de alimentação e nutrição.

BRASIL. Ministério da Saúde. Política nacional de alimentação e nutrição. Brasília, 1999.

BUSS, Dale D. Trimming the fact from fat replacer expectations. Food processing, Chicago, vol 55, $\mathrm{n}^{\circ} 2,1994$.

BYRNE, M. Fat replacers in focus. Chilton Food Engineering International, Radnor, vol 17, 1992.

CÂNDIDO, L. Alimentos para fins especiais: dietéticos. 2 .ed. São Paulo: Varela, 1996.

CARBALLO et al. Binding properties and colour of bologna sausage made with varying fat levels, protein levels and cooking temperatures. Meat Sci., Oxford, vol.41, 1995.

CARR, J. M. Hydrocolloids and stabilizers. Food Technology. Chicaco, vol 47, n¹0, 1993.

COUDRAY, C; TRESSOL, J. C. GUEUX, E; RAYSSIGUIER, Y. Effects of inulin-type fructans of different chain length and type of branching on intestinal absorption and balance of calcium and magnesium in rats. Europian Journal of Nutrition, vol. $42, \mathrm{n}^{\circ} 2$, 2003.

DAWKINS, N. L; PHELPS, O; McMILLIN, K. W; FORRESTER, I. T. Composition and physicochemical properties of chevon patties containing oat bran. J. Food Sci., vol. 64, $\mathrm{n}^{\circ} .4,1999$.

DE ANGELIS, R. C. Alimentos de origem vegetal são saudáveis: verdades e alguns questionamentos. Nutrição em Pauta, ano X, n. ${ }^{\circ}$ 57, 2002. 
DRAKE, M.A et al. Melting characteristics and hardness of milkfat blend sucrose polyesters. Journal off Food Science. Chicago, vol 59, 1994.

DUXBURY, D et al. Dietary fats \& oils. Food Processing. Chicago, vol 52, 1991.

DUXBURY, D. Low fat crunch from soy beans. Food processing. Chicago, vol 52, 1991.

DUXBURY. D. Pectin on your label can take fat off your table. Food Processing, Chicago, vol 52, 1991.

DYMINSKI et al. Características físico-químicas de mousse de maracujá elaborado com substitutos de gorduras. Departamento de Tecnologia Química, vol 18, nº.2, 2000.

DZIEZAK, J.D. A focus on gums. Food technology, Chicago, vol 45, 1991.

EGBERT W. R et al. Development of low-fat ground beef. Food Technology. Chicago, vol 45, 1991.

EWITT L. Gum set and match. Food Manufacture, London, vol 69, 1994.

EYDT A.J. Formulating Reduced fat foods with polyglycerol ester emulsifiers. Food Tecnology. Chicago, vol 48, 1994.

FDA ask questions about $\mathbf{P} \& \mathbf{G}$ 's caprenin. International News on fats, Oils and Related Materials. Champaign, vol 5, 1994.

FIGUEIREDO et al. Influência dos substitutos de gordura Animal sobre a qualidade da salsicha tipo Viena. Braz. J. Food Technol, 2002.

FILHO B. M; RISSIN A. A transição nutricional no Brasil: tendências regionais e temporais. Caderno Saúde Pública, Rio de Janeiro, 2003.

FUCHS et al. Iogurte de soja suplementado com oligofrutose e inulina. Ciência. Tecnológica de Alimentos, Campinas, 2005.

GIESE, J.H. Developing low-fat meat products. Food technology, Chicago, vol 46, 1992.

GUION, P. Les agents de sapidé. Industries Alimentaires et Agricoles. Paris, vol 111, 1994.

HAULY , O M.C; MOSCATTO A.J. Inulina e Oligofrutoses: uma revisão sobre propriedades funcionais, efeito prebiótico e importância na indústria de alimentos. Semina: Ciências Exatas e Tecnológica, Londrina, vol. 23, nº. 1, 2002.

HAYES, J.R. Review of triacylglycerol digestion, absorption, and metabolism with respect to SALATRIM triacylglycerols. Journal of Agriculture anf Food Chemistry. Washington, vol 42, 1994.

HEBBEL, Prof. Dr. Hermann Schmidt. Aditivos y Contaminantes de Alimentos. Editora Fundacion Chile. Santiago-Chile. 1979 
HENRY, D.E et al. Characterization of used frying oils. Comparision of Olestra and triglyceride. Journal of the American Oil Chemists`Society, Champaign, vol 69, 1992.

IBGE. Pesquisa de orçamento famíliar 2002-2003: Primeiros resultados - Brasil e Regiões. $2^{\mathrm{a}}$ edição, 2004.

IYENGAR, R; GROSS A. Fat substitutes. Biotechnology and food Ingredients. New York, 1991.

JANE et al. Anthology of starch granule morfology by scaning electron microscopy. Starch/Stärke, Weinheim, 1994.

KEETON, J. T. Low-fat meat products - Technological problems with processing. Meat Sci., Oxford, 1994.

KOPCHIK F. M. Reduced calorie bulk ingredients: Polydextrose and polydextrose II. The Manufacturing Confectioner, Chicago, vol 70, 1990.

LaBARGE, R.G. The search for a low caloric oil. Food Technology. Chicago, vol 42, 1998.

LAURENZO, K.S; NAVIA J.L; NEIDITCH D.S. Preparation of inulin products. USA Patent number 5,968,365. Oct. 19, 1999.

LEACH, H.W. Determination of intrinsic viscosity of starch. Cereal Chemistry, 1963.

LEE S. Y; MORR C. V; SEO A. Comparison of milk based and soymilk-based iogurt. Journal of Food Science, vol. 55, n 2, 1990.

LIMA, R. J; NASSU, T.R. Substitutos de gorduras em alimentos: características e aplicações. Química Nova, 1996.

LUCA, P.A; TEPPER, B.J. Fat replacers and the functionality of fat in foods. Trends in Food Sc. Technol. Cambridge, vol 5, 1994.

LUCCA, P.A; TEPPER B.J. Fat replacers and the functionality of fat in foods. Trend in Food Science \& Tecnology. Cambridge, vol 5, 1994.

MARINE colloids $\mathbb{R}$. The carrageenan people. Philadelphia: Introductory Bulletin Publicação técnica, 1991.

MASGNAUX, J.H. Gomme d’acacia ou gomme arabique: une fibre alimentaires hautement soluble. Industries Alimentaires et Agricoles, Paris, vol 111, 1994.

Ministério da Saúde. Análise de Evidencias da Estratégia Global da Organização Mundial de Saúde para Alimentação Saudável, Atividade Física e Saúde. Documento realizado pelo Grupo técnico assessor instituído pela Portaria ${ }^{\circ}$ 596, de 8/4/2004. Disponível em: http://www.saude.gov.br/alimentacao e www.saude.gov.br/svs.

MONDINI L; MONTEIRO C. Mudanças no padrão de alimentação da população urbana brasileira (1962-1988). Revista Saúde Pública, vol 28, nº 6. São Paulo, 1994. 
MONTEIRO, C. A. (Org.) Velhos e novos males da saúde pública no Brasil: a evolução do país e de suas doenças. São Paulo: Hucitec / Nupens / USP, 2001.

MOSCATTO et al. Farinha de yacon e inulina como ingredientes na formulação de bolo de chocolate. Ciência e Tecnologia de Alimentos, Campinas, out-dez, 2004.

NABESHIMA et al. Propriedades físicas do sorvete de baunilha elaborado com substitutos de gordura e sacarose. B. CEPPA, Curitiba, vol 9, 2001.

NABISCO files GRAS petition for faty acid triacylglicerois. Food Chemical News. Washington, vol 36, 1994.

OLIVEIRA et al. Otimização de extração de inulina de raízes de chicória. Revista Brasileira de Produtos Agroindustriais, Campina Grande, vol.6, $\mathrm{n}^{\circ} .2,2004$.

ORNELLAS et al. Efeito da adição de Nacl sobre as propriedades funcionais do plasma bovino e de seus hidrolisados trípticos. Ciência Tecnologia de Alimentos: vol $20, \mathrm{n}^{\circ} 3$, 2000 .

ORNELLAS, C. B. D. Propriedades funcionais de globina, plasma e seus hidrolisados enzimáticos obtidos do sangue bovino. Dissertação (Mestrado) - Faculdade de Farmácia da UFMG, Belo Horizonte, 2000.

PSZCZOLA, D. E. Starches and gums move beyond fat replacement. Food Technology, vol. $53, \mathrm{n}^{\circ} .8,1999$.

RAKES, G; REYNOLDS, J.M. Soy protein concentrate in low-fat foods. Food Marketing \& Tecnology. Nuremberg, vol 6, 1992.

RICE, R. Health claims on food supplement labels. British Food Journal. Bradford, vol 95, 1993.

ROBINSON, R.K. The potential of inulin as a functional ingredient. British Food Journal. Bradford., vol 97, n. ${ }^{\circ} 4,1995$.

ROSENTHAL, F.R.T., NAKAMURA, T., ESPINDOLA, A.M.C., JOCHIMEK, M.R. Structure of starch granules. Die Stärke, Weinheim, 1974.

SETSER C. S; RACETTE W. Macromolecule replacers in food products. Critical Reviews in Food Science and Nutrition. Boca Raton, vol 32, 1992.

SHAND et al. Kappa - carrageenan, sodium chloride and temperature affect yield and texture of structured beef rolls. Journal of Food Science, Chicago, vol 59, 1994.

SILVA, R. F. Use of inulin as a natural texture modifier. Cereal Foods World. St. Paul: vol 41, n.10, 1996.

SIVIERI K; OLIVEIRA M.N. Avaliação da vida-de-prateleira de bebidas lácteas preparadas com "fat replacers". Ciência e Tecnologia dos Alimentos vol 22, $\mathrm{n}^{\circ} .1$ Campinas, 2003. 
SOARES et al. Influência do concentrado protéico de soro na composição do requeijão em barra com teor reduzido de gordura. Arquivo Brasileiro de Medicina Veterinária e Zootecnia vol.54 n.6, Belo Horizonte, 2002.

SOBCZYNSKA, D; SETZER, C.S. Replacement of shortening by maltodextrinemulsifier combinations in chocolate layer cakes. Cereal Foods World, St Paul, vol 36, 1991.

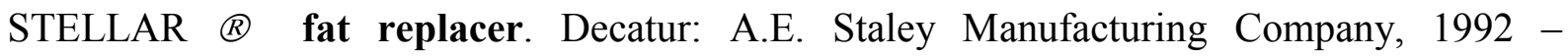
Publicação Técnica.

TROY, D. J; DESMOND, E. M; BUCKEY D. J. Eating quality of low-fat beef burgers containing fat-replacing functional blends. J. Sci. Food Agric, 79, 1999.

TUCOULAT, R. Les emulsifiantes. Inustries Alimentaires e Agricoles. Paris, vol 111, 1994.

UMBElinO, D. C; CARDELlO, H. M. A. B; ROSSI, E.A. Efeito de diferentes sais de ferro sobre as características sensoriais do "iogurte"de soja. Archives Latinoamericanos of Nutrition, vol. 51, $\mathrm{n}^{\circ} .2,2001$.

VIANA et al. Efeito da substituição parcial da gordura pela globina e plasma bovinos em patê de presunto. Maringá, vol 25, n 1, 2003.

WHO. Diet, nutrition and the prevention of chronic diseases. Report of a Joint WHO/FAO Expert Consultation. Geneva: World Health Organization. WHO Technical Report Series, 916, 2003. Disponível em:<http://www.who.int/dietphysicalactivity/en/

YAZICI F; ALVAREZ V. B; HANSEN P. M. T. Fermentation and properties of calciumfortified soy milk yogurt. Journal of Food Science, vol. 62, nº. 3, 1997.

ZAMBRANO et al. Efeito das gomas guar e xantana em bolos como substitutos de gordura. Instituto de Tecnologia dos Alimentos - ITAL, 2005.

ZAMBRANO M. F; CAMARGO O.R. Substitutos de gorduras: Efeito da Concentração de Ácido e do Tempo de Hidrólise do Amido de mandioca em algumas características dos hidrolisados. Faculdade de Engenharia de Alimentos - Unicamp, 1999.

ZAMBRANO M. F; CAMARGO O.R; TAVARES D. Amido de Mandioca Modificado Comparado com Substitutos de Gordura Comerciais. Braz. J. Food Technol, 2001. 